\title{
CFD Analysis of Port Water Injection in a GDI Engine under Incipient Knock Conditions
}

\author{
Jacopo Zembi ${ }^{1, * \mathbb{C}}$, Michele Battistoni ${ }^{1}$, Francesco Ranuzzi ${ }^{2}$, Nicolò Cavina ${ }^{2}$ and \\ Matteo De Cesare ${ }^{3}$ \\ 1 Department of Engineering, University of Perugia, 06125 Perugia, Italy \\ 2 Department of Industrial Engineering, University of Bologna, 40136 Bologna, Italy \\ 3 Magneti Marelli Powertrain, 40131 Bologna, Italy \\ * Correspondence: jacopo.zembi@unipg.it; Tel.: +39-075-585-37-49
}

Received: 10 July 2019; Accepted: 30 August 2019; Published: 4 September 2019

check for updates

\begin{abstract}
This paper investigates, through computational fluid dynamics (CFD) simulations, the knock resistance improvements that can be obtained in a turbo-charged GDI engine with water injection. In a first step, water and gasoline injector models are validated comparing the results with experimental data from constant volume chamber tests. Then, multi-cycle simulations are performed using the G-equation turbulent combustion model focusing on spray evolution and wall film dynamics. The main intent is analyzing the effectiveness of different water injection timings and injection pressures in a port water injection (PWI) installation. Combustion rates are validated against experimental engine data, with and without water injection. Afterwards, in order to predict autoignition behavior with different spark advance (SA) timings, the extended coherent flamelet model (ECFM) combined with a tabulated kinetic ignition (TKI) dataset is used. End-gas autoignition delays are calculated using a reduced mechanism for toluene primary reference fuel (TPRF), which revealed essential for capturing actual gasoline ignition characteristics. Results indicate that the water atomization quality, i.e., injection pressure, is significant in a PWI installation allowing a reduction of the water wall film formation in the ports. Water injection timing needs also to be carefully chosen for optimized performance. As the injected water allows the SA to be increased, the overall benefits on indicated mean effective pressure and fuel consumption are quantified under the same knock safety margin, matching adequately well the available measurements.
\end{abstract}

Keywords: port water injection; knock; knock-limited spark advance; turbo-charged GDI engine; CFD simulation; tabulated kinetic ignition

\section{Introduction}

The injection of water in turbocharged gasoline direct injection (GDI) engines has gained increased attention as a viable technology for achieving significant $\mathrm{CO} 2$ reduction and increasing performance. The injection of liquid water causes a reduction of the charge temperature, changes its thermo-dynamic properties, and dilutes the combustible mixture, enabling the adoption of more efficient spark timings and the reduction of combustion and exhaust gas temperatures. Improved spark timing can be used at high load, relaxing the knock-limited spark advance (KLSA) constraint. This can allow the adoption of higher compression ratios with benefits on the whole engine operating map. Fuel enrichment to reduce the thermal stresses of hot engine components can be avoided, providing fuel savings of up to $15-20 \%$ at high loads. The reduction of combustion temperatures is also an effective method for NOx control that could replace EGR usage in some strategies [1-6].

Substantial benefits can already be obtained by injecting water into the intake manifold, with a relatively cheap technology. It is known that direct water injection inside the cylinder is more 
effective, requiring almost half of the water compared to a port installation, for the same efficiency gain [4]. In PWI configurations, which are the most viable solutions for many engine manufacturers, specific spray optimization work is required, to optimize targeting and timing and to limit port wall impingement. Installations very close to the inlet valves can achieve almost the same effectiveness of direct injection solutions $[4,7,8]$.

Many experimental works $[2,6,9]$ report on the effects of changing key control parameters, such as water injection timing and quantity, or adjusting spark timing to maximize efficiency or performance. In some cases, up to over $100 \%$ of water-to-fuel mass ratio is used, even if it seems acknowledged that most of the benefits are generally achieved with a ratio not exceeding $50 \%[1-3,6,8,9]$, as further marginal improvements come at a too high cost of water consumption. The optimal water amount, however, heavily depends on the engine point that is being considered. To provide some useful figures, a recent state-of-the-art work published by Thewes et al. [2] is quickly reviewed. The work shows successive gain steps achieved by applying water injection. In the baseline engine a $\sim 3 \%$ fuel consumption reduction is achieved with direct water injection, while the range of optimal combustion phasing over the engine map is extended from a maximum of $\sim 10$ bar IMEP up to 18 bar IMEP. After increasing the compression ratio of about 1 point and optimizing cam profiles, the authors report, using vehicle simulations calibrated against test bench data, that $\sim 2.5 \%$ fuel efficiency gain can be achieved on WLTP, NEDC and RTS 95 driving cycles, with increasing amount of water consumptions, ranging from 0.5 to $3 \mathrm{~L} / 100 \mathrm{~km}$.

The physical aspects that play a role when liquid water is introduced in an engine can be identified in the following list:

- Charge cooling due to water evaporation, before combustion takes place.

- Charge dilution that slows down flame speed and delays autoignition, because of combined effects of reduced chemistry speed and increased mixture heat capacity in presence of water vapor.

- Modified ratio of specific heats $\left(\gamma=c_{\mathrm{p}} / \mathrm{c}_{\mathrm{v}}\right)$ which affects compression and expansion work and the overall efficiency.

Concerning the first aspect, if the temperature reduction due to evaporation occurs early in the intake stroke, the gain approaching combustion is then leveraged by the compression, therefore the effect is maximized. Also, vaporizing in the port causes a reduction of the volumetric efficiency which is undesirable, therefore, the major goal of a PWI strategy is for the water to reach the cylinder and to evaporate inside the chamber before the intake valve closure (IVC) occurs. Generally, this requires optimized control to limit impingement on the port walls, which otherwise would reduce the charge cooling effect if the vaporization is sustained by heat transfer from the walls.

The second point is charge dilution operated by water vapor. It causes a favorable increase of autoignition delays of the mixture, but at the same time a reduction of the laminar flame speed, similar to what is generally achieved by recirculating combustion products (EGR). The main difference with EGR is in absolute terms, as the amount of water vapor mass is generally not very high as compared to possible EGR levels. Considering that injected water is generally a fraction of the fuel mass, it can roughly reach $2-5 \%$ of equivalent dilution ratio. Dilution effect combines with the charge cooling effect, and generally both contribute to the overall reduction of the combustion temperature and to the reduction of knock risk. This can result in lower NOx and/or lower exhaust gas temperatures, depending on the engine point or strategy.

As for the last thermodynamic aspect related of the working fluid properties, here, two effects combine. Triatomic water vapor molecule lowers the $\gamma$ of the mixture and, therefore, the corresponding ideal cycle efficiency; at the same time, the mixture cooling due to evaporation brings down the temperature which in turn rises $\gamma$. According to [3], since the heat capacity ratio strongly depends on the temperature level the latter effect might overcompensate the efficiency decrease expected when adding triatomic molecules. Taking this into account, it is however quite difficult to isolate the $\gamma$ effect with respect to the previous two. The overall impact can also depend on the water injection strategy. 
An experimental study conducted by Chen et al. [10] shows that the first effect due to charge cooling has a lower impact, compared to the combination of the second and third effects due to changing the thermodynamic properties of the working fluid, which tend to have larger impacts.

Numerical simulations can assist in designing water injection systems and in understanding the intertwined phenomena occurring from the water spray to the combustion. Some examples of CFD studies have been presented recently in the literature [7,11]. Two aspects combine: the realistic modeling of the water injection process and the robust knock risk prediction. Spray model validations are mandatory, for a proper description of the water and fuel distribution in the ports and in the cylinders. Concerning SI combustion modeling, it has been clearly shown that large eddy simulation (LES) is the proper method to account for all statistical phenomena from flame propagation to autoignition [12], at the expense of costly multi-cycle simulations. Tabulated kinetics for ignition (TKI) coupled with the extended coherent flamelet combustion model (ECFM) it is shown to provide high accuracy in predicting knock frequency and intensity. However, RANS is still the method of choice for large number of design space explorations $[7,11,13-16]$. Some authors are proposing new advanced models with presumed probability distribution functions to include knock statistics upfront in RANS [14,15]. More simply, Berni et al. [13] coupled a TKI model to the ECFM flame propagation model, to study water injection effects in a boosted V8 engine with satisfactory results. Similarly, in order to decouple auto-ignition and flame propagation, Chevillard et al. [16] proposed a computational RANS approach based on ECFM and TKI, and with the imposed stretch spark ignition model (ISSIM) to represent spark ignition.

In this work we first show validations of an overall engine model, then we investigate how port water injection affects combustion, and lastly, we quantify the IMEP gain that can be achieved adding water and reoptimizing the spark timing. The main purpose is a fundamental study on water injection effects and behavior using CFD. Several engine cycles are needed to reach a stable water wall film in the intake ports. Due to the costly method requiring multi-cycle simulations because of the port injection, we limited our range of investigation to a single engine baseline point, under a KLSA operating condition. We explored different water injection timings and pressures to assess the effectiveness of a fixed amount of water. A well validated G-equation combustion model was used to simulate multiple-cycles efficiently. Spark sweeps were then carried out by restarting the simulations on the last cycle slightly before the ignition, and adopting the ECFM model for the combustion coupled with TKI to add autoignition prediction capability. The CFD results allowed to assess the charge cooling effect, the burning rate reduction and, ultimately, the power increase under the same KLSA criterion.

\section{Engine Description and Computational Setup}

\subsection{Experimental Setup}

The engine used for the investigation is a 1.4 liter 4-cylinder engine with supercharger and turbocharger, featuring direct fuel injection, a compression ratio of 10:1, and a maximum brake mean effective pressure (BMEP) of $\sim 20$ bar. The main engine specifications are reported in Table 1 .

The engine is equipped with a GDI fuel injection system, and the target working condition, without water injection, is defined by an average inlet manifold pressure of $1.5 \mathrm{bar}$ (abs) at $2500 \mathrm{rpm}$. The set of parameters is shown in Table 2, and the resulting engine load is about 14 bar indicated mean effective pressure (IMEP). Water is injected upstream of each runner, controlling the water start of injection, pressure and duration [9]. In this paper, the analysis focuses on a fixed water-to-fuel mass ratio of $30 \%$. 
Table 1. Engine specifications.

\begin{tabular}{cc}
\hline Engine Specifications & Value \\
\hline Displaced volume & $1390 \mathrm{~cm}^{3}(4 \mathrm{cylinders})$ \\
Stroke & $75.6 \mathrm{~mm}$ \\
Bore & $76.5 \mathrm{~mm}$ \\
Compression ratio & $10: 1$ \\
Valves per cylinder & 4 \\
Intake valve opening/closing & $372 / 588$ CAD aTDCf \\
Exhaust valve opening/closing & $140 / 364$ CAD aTDCf \\
Fuel & Commercial Gasoline RON $=95, \mathrm{MON}=85$ \\
Max torque & $220 \mathrm{Nm}$, at $1500-4000 \mathrm{rpm}$ \\
Max power & $103 \mathrm{~kW}$ at $6000 \mathrm{rpm}$ \\
\hline
\end{tabular}

Table 2. Operating point specifications.

\begin{tabular}{cc}
\hline Operating Point Specifications & Value \\
\hline Engine speed & $2500 \mathrm{rpm}$ \\
Equivalence ratio $(\Phi)$ & 1.0 \\
Injected fuel mass & $35.19 \mathrm{mg}$ \\
GDI injector nozzle & $5 \mathrm{holes}$ \\
Injected fuel temperature & $343 \mathrm{~K}$ \\
Start of injection (SOI) & $-276.5 \mathrm{CAD} \mathrm{aTDCf}$ \\
Duration of injection & $59.5 \mathrm{CAD}$ \\
Gasoline injection pressure & $110 \mathrm{bar}$ \\
Spark timing & $-14 \mathrm{CAD}$ aTDCf \\
Intake manifold pressure (ave.) & $1.5 \mathrm{bar}$ \\
Exhaust pressure (ave.) & $1.8 \mathrm{bar}$ \\
\hline
\end{tabular}

\subsection{Computational Setup}

The CFD model is built for a single-cylinder configuration, cutting out just one cylinder from the original 4-cylinder geometry [7]. Figure 1 shows the geometry and how the CFD analyses were set up. Water injector and gasoline injector locations are highlighted with white cones in Figure 1a and an example of spray patterns is shown with blue and red parcels, respectively, in Figure 1b. The airbox has been replaced by the hemispherical region positioned at the inlet of the single runner configuration. Being aware that during the closed valve period some water droplets could travel backwards toward the inlet boundary, because of convection or pressure waves, we checked simulation results and verified that no water mass was lost in any analyzed case. Therefore, the adopted inlet region (grey in Figure 1a) is considered adequate for the scope of this work. The CONVERGE CFD solver [17] has been used in this study, which uses a modified cut-cell Cartesian gridding method to automate the creation of the mesh at runtime (Figure 1c). Various fixed and adaptive meshing refinement strategies were used, ad-hoc temporally and spatially activated, to achieve $0.75 \mathrm{~mm}$ cell size in sprays and combustion areas. Around spark a resolution of $0.1875 \mathrm{~mm}$ was used $[7,18]$. More details are provided later in Section 3.1. Overall, this grid management allows for an adequate mesh resolution while keeping the maximum cell count below 1 million, in favor of the simulation turnaround time. As a result, a typical simulation takes about 15 hours per engine cycle on 40 cores.

Momentum, continuity, energy, species, and turbulence conservation equations have been solved, using second order accurate spatial discretization schemes, and implicit first order time scheme. The time integration uses a variable time-step algorithm controlled by the local convective Courant number. Turbulence is modeled using the Re-Normalization Group (RNG) k- $\varepsilon$ turbulence model, which is largely accepted as the de-facto model for unsteady RANS simulations of internal combustion engines $[19,20]$. Liquid water and fuel sprays are modeled with the typical Lagrangian method. The primary atomization in not modeled and a prescribed distribution of droplet diameters is assigned, using the Rosin-Rammler (RR) probability density function and the Sauter mean diameter. Experimental 
measurements of droplet sizes for each injector have been used to setup the corresponding spray models (see next section). Secondary breakup can then occur upon injection, following Rayleigh-Taylor and Kelvin-Helmholtz models. Spray models also include appropriate sub-models for droplet turbulence dispersion, collision, evaporation, and wall film formation, setup according to our previous experience and the general accepted literature [7]. Inlet and outlet pressure boundary conditions and wall temperature conditions are extracted from a validated 1D engine cycle model and measurements collected on the engine dyno [9].

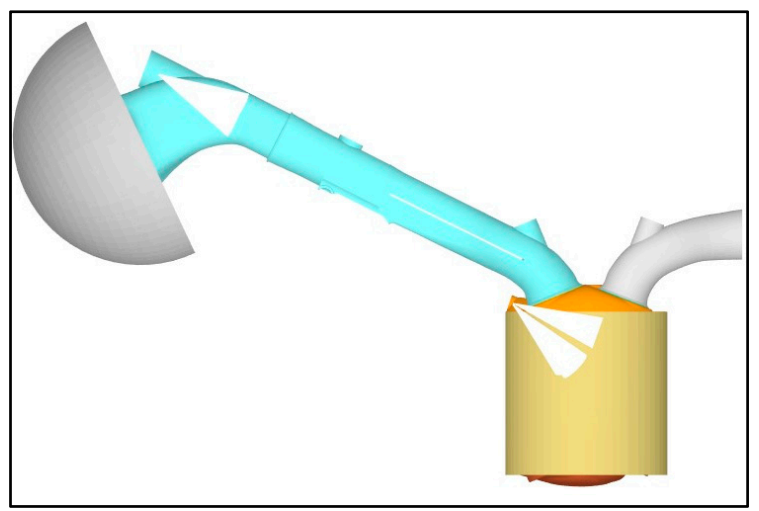

(a)

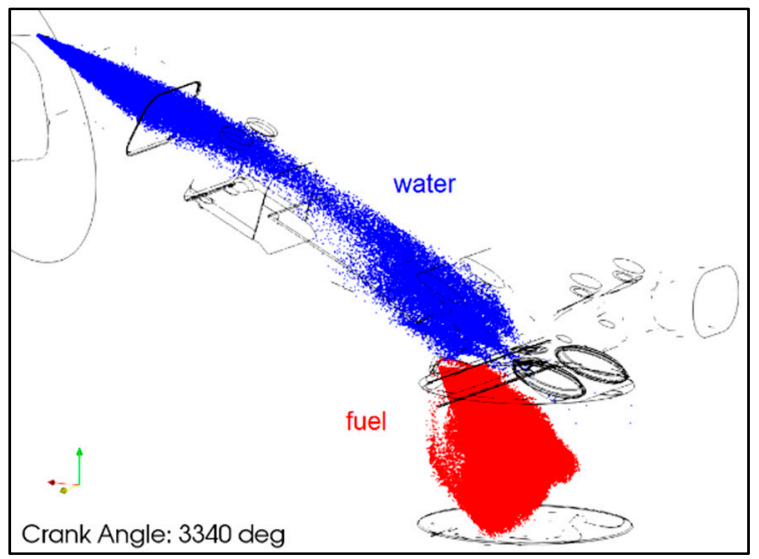

(b)

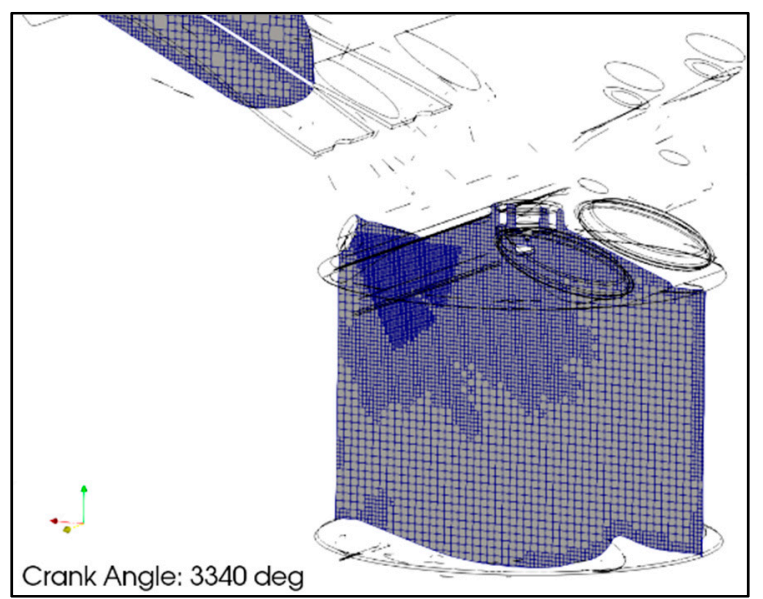

(c)

Figure 1. CFD engine model. (a) Geometry with injector locations; (b) Water and gasoline spray visualization; (c) Mesh. 
As mentioned in the Introduction, two approaches have been used for combustion modeling. For multi-cycle runs we adopted the fast G-equation model, by Peters [21]. This model tracks the flame-front surface using the level-set method, and it is appropriate for premixed and partially premixed turbulent combustion cases. Ignition is modeled by sourcing the passive $G$ in a sphere of $0.5 \mathrm{~mm}$ radius located in the spark electrode gap, for $5 \mathrm{CAD}$. The laminar flamespeed, $S_{L, 0}$, is calculated with Gulder correlation for gasoline [22]. The effect of water on the laminar flame speed $S_{L}$ is accounted for using the following empirical equation [23]:

$$
S_{L}=S_{L, 0}\left(\frac{T_{u}}{T_{u, 0}}\right)^{a}\left(\frac{p_{u}}{p_{u, 0}}\right)^{b}\left(1-2.1 Y_{d i l}\right)
$$

where the mass fraction of water influences the value of the dilution species mass fraction, $Y_{d i l}$.

The formulation of the turbulent flame speed, $S_{T}$, takes the form proposed by Peters [21]:

$$
S_{T}=S_{L}+u^{\prime}\left\{-\frac{a_{4} b_{3}^{2}}{2 b_{1}} D a+\left[\left(\frac{a_{4} b_{3}^{2}}{2 b_{1}} D a\right)^{2}+a_{4} b_{3}^{2} D a\right]^{0.5}\right\}
$$

where $u^{\prime}$ is the root-mean-square of the turbulent velocity fluctuations, $a_{4}, b_{3}$ and $b_{1}$ are model constants, and $D a$ is the Damkohler number. The combustion model has been tuned by adapting the value of the model constant $b_{1}$ in the baseline case (without water).

In order to explore auto-ignition under different SA timings, in the last cycle, after proper mapping and restarting of the calculations, we switched to the ECFM combustion model with a TKI table. The ECMF implementation follows the recent species-based model described in [16]. Flame speed correlation and effect of water dilution remained the same as described above, in Equation (1). Concerning the autoignition model, to generate the TKI table we used the semi-reduced mechanism by Andrae et al. [24] for toluene primary reference fuel mixture (TPRF; mixture of toluene, iso-octane and n-heptane), comprising 138 species and 633 reactions. The TPRF mixture, with blending rules according to Morgan et al. [25], represents a RON $=95$ and $\mathrm{MON}=85$ gasoline. The following composition is used: toluene $60.54 \%$, iso-octane $20.5 \%$, $n$-heptane $18.82 \%$ by vol. [25]. The advantage of including tabulated kinetics for autoignition lies primarily in the light computational cost, and also in the possibility of decoupling flame propagation from end-gas autoignition. It is worth noticing that in a RANS context, this combustion approach is not meant to provide statistical information on the occurrence of knock, but it is rather a model for ensemble averaged behavior, therefore it only provides a description of the average cycle.

\section{Spray Validation}

In order to build a reliable engine model, we preliminary focused on the accurate setup and validation of the spray sub-models. Magneti Marelli is the manufacturer of both water and gasoline injectors and provided experimental data collected in a constant volume vessel. The following sub-sections provide further details on this initial step of the work.

\subsection{Port Water Injector}

The water injector characteristics are given in Table 3. The injector features a three-hole nozzle, with almost parallel and interacting jets lying on the same plane. All the three holes have been modeled so that the global asymmetric spray morphology is naturally reproduced. Injection rates and a population of atomized droplets based on RR distributions are prescribed as boundary conditions. Three injection pressures have been explored, namely 3, 6, and 9 bar, with an initial Sauter mean droplet diameter (SMD) of 74, 65, $60 \mu \mathrm{m}$, respectively. These values have been selected after a preliminary calibration based on the comparison of the simulated spray droplet sizes against measurements. As an example, we show here the validation results for the 6 bar case, as reported in Table 3. In a first step, 
a simulation campaign has been carried out to assess the effect of the grid size. When refining the grid, a corresponding increase of the number of injected parcels is considered [18]. Results are shown in Figure 2. The minimum mesh size is achieved with four levels of refinements below the base size, by a combination of fixed embedding and adaptive mesh refinement (AMR) techniques. Penetration curves have similar trends, and below $0.75 \mathrm{~mm}$ minimum grid size grid independence is achieved. Taking also into account the simulation cost, the minimum grid size of $0.375 \mathrm{~mm}$ (base grid size $=6$ $\mathrm{mm}$ ) has been selected for the subsequent engine analyses. The second step has been the validation of the droplet size at downstream locations. Figure 3 shows a comparison of the measured and predicted SMD (D32) and average diameter (D10), at $15 \mathrm{~mm}$ from the injector tip ( $z$ direction). Simulations are able to reproduce experimental trends and values in a satisfactory manner. Only minor differences can be observed, as the experimental curves show a mild peak in the center that is less evident in the simulations.

Table 3. Water Injector and vessel test conditions for 6 bar inj. pressure case.

\begin{tabular}{cc}
\hline Test Conditions & Value \\
\hline & 3 holes \\
Nozzle type & Hole diameter $=140 \mu \mathrm{m}$ \\
& Global spray angle $=\alpha \mathrm{F}=26^{\circ}$ (front view) \\
& Global spray angle $=\alpha \mathrm{L}=28^{\circ}$ (lateral view) \\
& Spray axis angle $=\beta=6^{\circ}$ \\
Near cone angle $=26^{\circ}$ \\
Spray boundary condition & Pre-atomized drops, using a Rosin Rammler \\
& distribution with SMD $=65 \mu \mathrm{m}$ \\
Fluid injected & Cd $=0.74$ \\
Injected mass & $8.39 \mathrm{mg}$ \\
Injected fluid temperature & $298 \mathrm{~K}$ \\
Injection pressure & $6 \mathrm{bar}$ \\
Injection duration & $373 \mathrm{~K}$ \\
Chamber temperature & $1 \mathrm{bar}$ \\
Chamber pressure & 7.635 ms (hydraulic duration) \\
\hline
\end{tabular}

\subsection{Port Water Injector}

Similarly, the GDI injector has been tested in a constant volume chamber, under the conditions shown in Table 4. In the vessel experiments the test fuel is Exxsol-D40, whose properties have been represented with an ad-hoc surrogate created only for the scope of this validation. Specifically, liquid phase properties have been prescribed to match density, viscosity, heat of vaporization, specific heat and surface tension in the range of temperatures of interest. Vapor phase has been modeled as iso-octane. Figure 4 shows a visual comparison between the simulated spray and the experimental imaging. The bottom-right figure, obtained via laser sheet imaging, allows to determine the actual directions of the jets, an essential information for the Lagrangian spray model, as in this type of injectors jets emerging from each hole depart considerably from the nominal drilled direction. Observing both the frontal and the side views, the comparison between the measured and simulated spray morphology were considered adequate. In addition, as for the water injector case, validations of the predicted penetration and droplet diameters have been carried out against available measurements, even if not reported here for the sake of conciseness. 

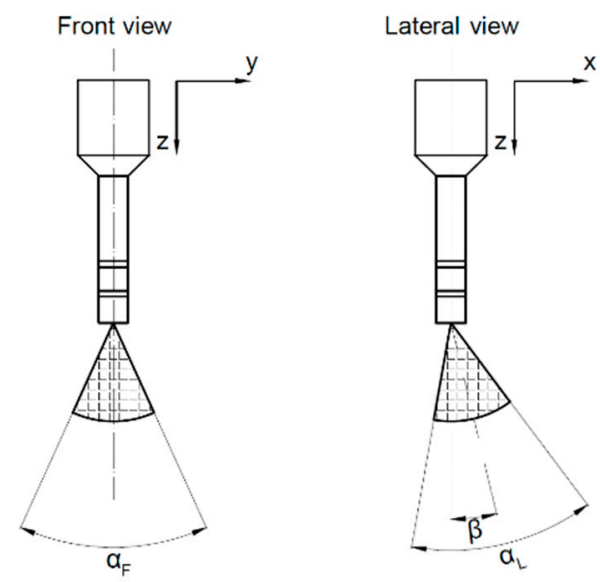

(a)

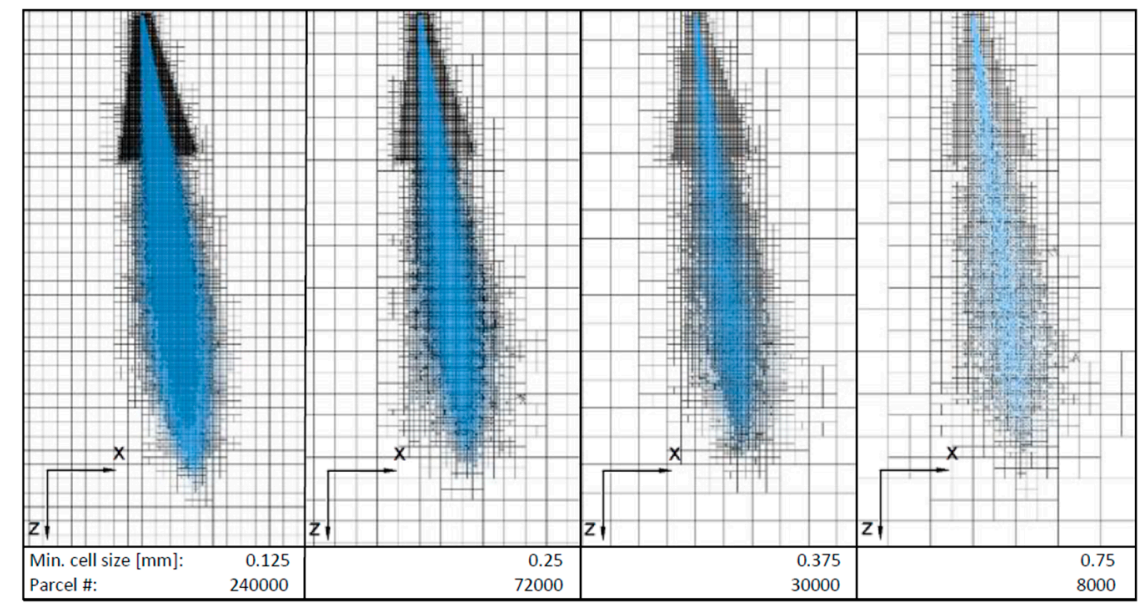

(b)

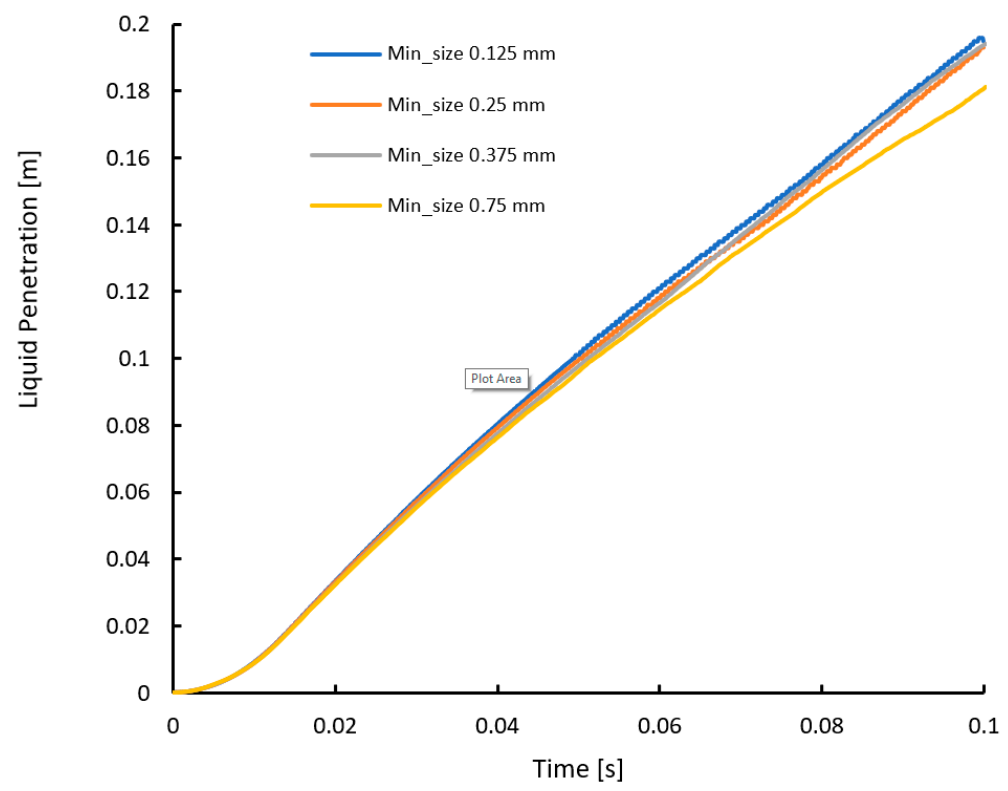

(c)

Figure 2. Spray angles definition (a), grid size effects on spray patterns (b) and on tip penetration (c) under conditions specified in Table 3. 


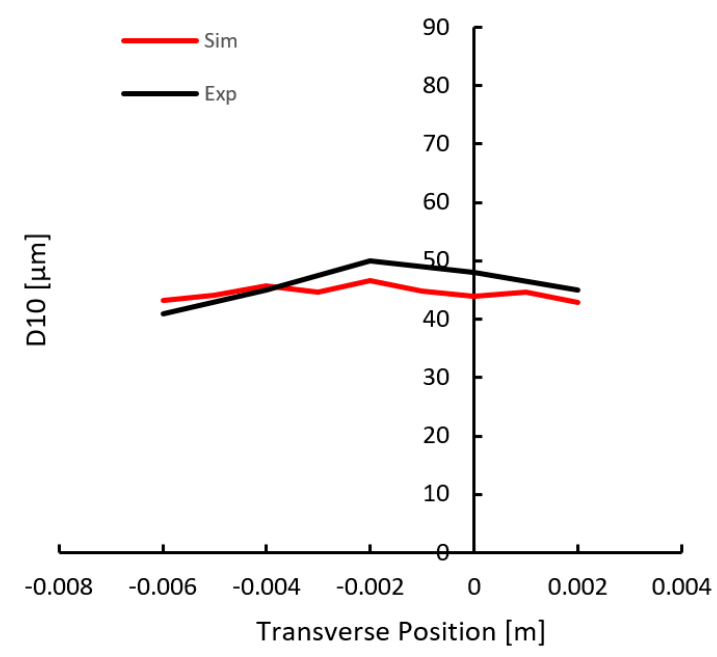

(a)

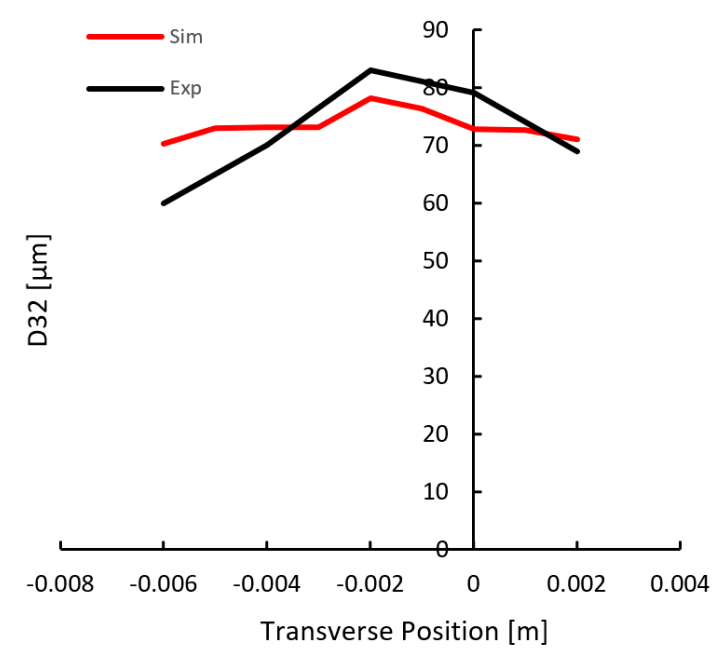

(b)

Figure 3. Comparison of simulated and measured droplet diameters at various transverse locations at $15 \mathrm{~mm}$ from the tip under conditions specified in Table 3. (a) average diameter (D10); (b) predicted SMD (D32).

Table 4. Gasoline Injector and vessel test conditions.

\begin{tabular}{cc}
\hline Test Conditions & Value \\
& 5 holes \\
Nozzle type & Hole diameter $=175 \mu \mathrm{m}$ \\
& Global spray angle $=82^{\circ}$ (front view) \\
Global spray angle $=54^{\circ}($ lateral view) \\
Spray axis angle $=\beta=6^{\circ}$ \\
Near cone angle $=20^{\circ}$ \\
Spray boundary condition & Pre-atomized drops, using a Rosin Rammler distribution with SMD = $15 \mu \mathrm{m}$ \\
& Cd $=0.603$ \\
Fluid injected & Exxsol-D 40 \\
Injected mass & 5.37 mg \\
Injected fluid temperature & $298 \mathrm{~K}$ \\
Injection pressure & $100 \mathrm{bar}$ \\
Injection duration & $298 \mathrm{~K}$ \\
Chamber temperature & 1 bar \\
Chamber pressure & $0.6 \mathrm{~ms}$ (hydraulic duration) \\
\hline
\end{tabular}



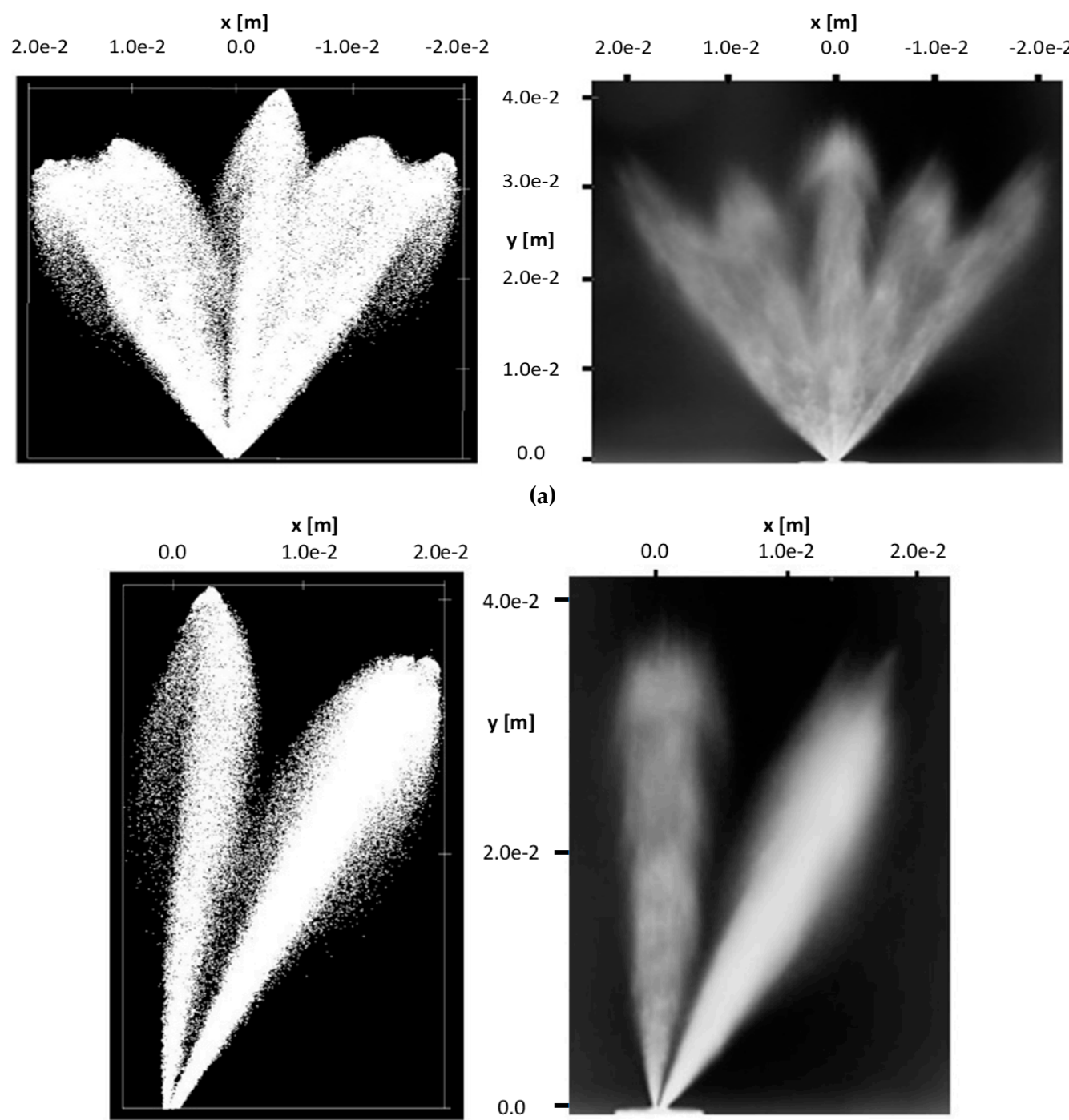

(a)

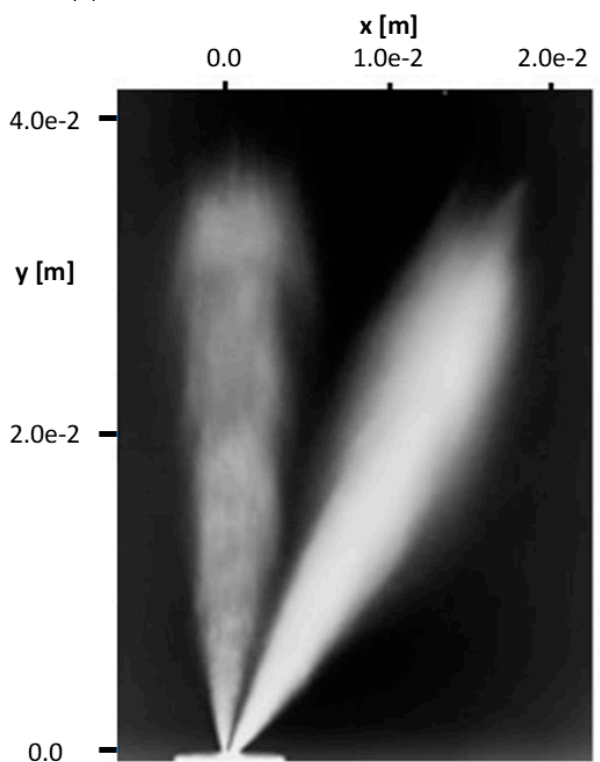

(b)
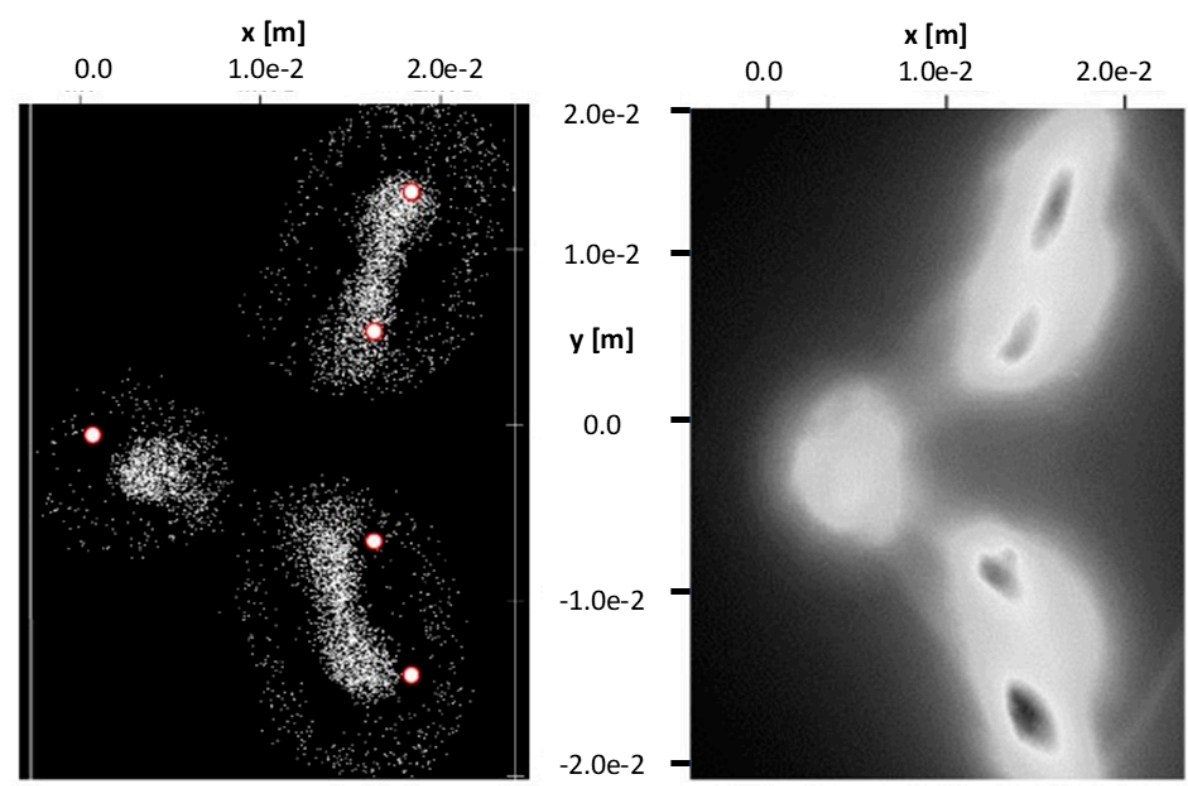

(c)

Figure 4. Comparison of spray simulations (left) and experimental imaging (right) at $0.5 \mathrm{~ms}$ from SOI: front (a), side (b) and bottom view at $30 \mathrm{~mm}$ from the injector tip (c). Conditions as in Table 4. 


\section{PWI Multi-Cycle Simulations}

The PWI injection generally causes impingement on the port walls or on the valves, and complex film dynamics is generated. Multiple cycles are required to model these phenomena. In the current implementation of the ECMF combustion model it is not possible to handle more than one liquid species, therefore multicycle analyses have been conducted using the G-equation combustion model which has no restrictions in this regard and allows to have two different injectors with different liquids. The baseline SA of -14 CAD after top dead center firing (aTDCf) is knock-free, hence calculations with G-equation are properly conducted. Within this framework, the focus of the first part of the work is on the amount of in-cylinder trapped water, on the amount of charge cooling due to evaporation, and on the pressure peak reduction with fixed SA. Later, in the second part of the study, we will switch to the ECFM+TKI combustion model to investigate knock occurrence by varying spark advance. As visible from the example in Figure 5a, the engine behavior becomes generally repeatable from the third cycle. For each case we run up to ten cycles and discarded the first two cycles for computing averages where necessary. In order to specifically validate the G-equation combustion model, a preliminary calibration has been conducted on the baseline model without water injection by tuning the model constant $b_{1}$ (cf. Equation (2)) to match experimental pressure traces, as shown in Figure $5 \mathrm{~b}$. A value of $b_{1}=5.5$ has been selected and then used for all the subsequent analyses, including all the cases with water addition. Figure $5 \mathrm{~b}$ shows the final comparison for the baseline case, between the computed in-cylinder pressure and the experimental trace, averaged over 200 measured cycles. The motored part is perfectly matched and the combustion is very well reproduced.

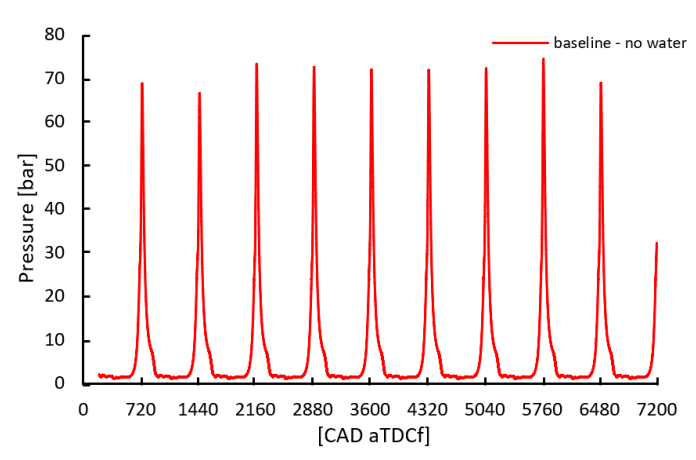

(a)

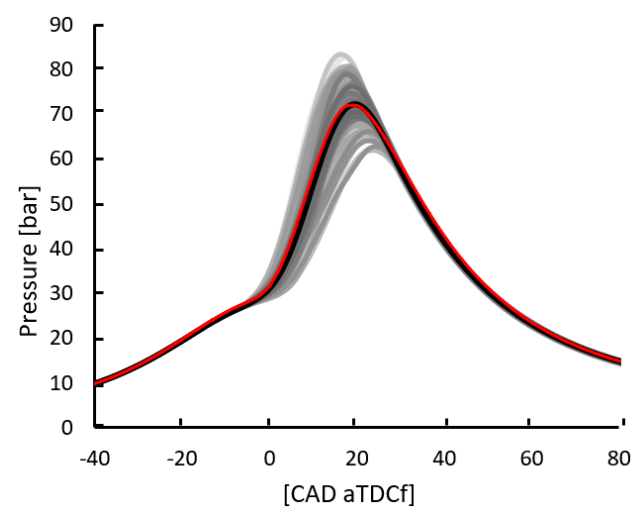

(b)

Figure 5. Example of multi-cycle simulations for the baseline configuration without water injection (a), and comparison of measured pressure (average curve in black, 200 cycles in gray) vs. simulated in-cylinder pressure (in red) (b).

The analyzed water injection cases are specified in Figure 6a. Five water SOI timings are considered at 3 bar injection pressure, ranging from 0 CAD to 540 CAD aTDCf. In addition, three pressure levels with equal SOI of 300 CAD aTDCf are investigated, namely 3, 9 and 20 bar, to assess the effect of the injection pressure. Water mass is fixed at a 0.3 water-to-fuel ratio, and the injected water temperature is set to $308 \mathrm{~K}$. Special care was devoted to prescribing wall temperatures for the critical part of the intake port and runner surfaces. Based on the engine speed-load point and on available measurements, we prescribed a spatially varying wall temperature, with a linear variation from $330 \mathrm{~K}$ in the upstream part of the duct up to $420 \mathrm{~K}$ just before the intake valve. 


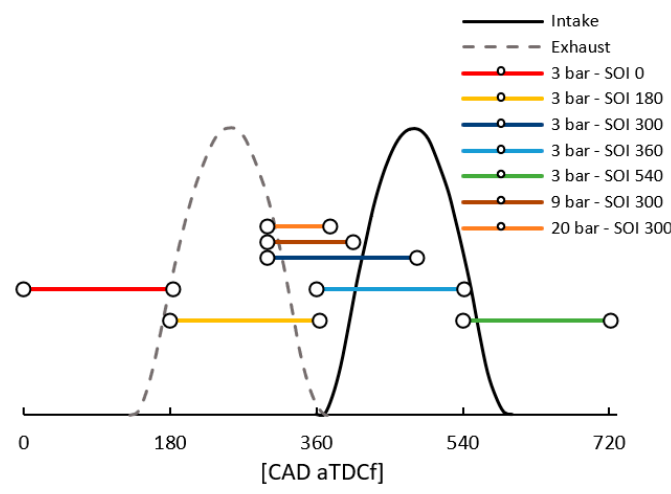

(a)

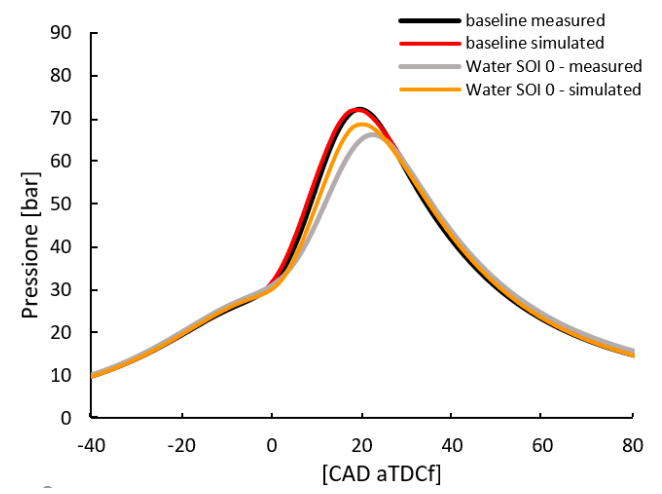

(b)

Figure 6. Timing and duration of each water injection case (a), and comparison of measured vs. simulated in-cylinder pressure (b).

Figure $6 \mathrm{~b}$ shows the comparison between the computed in-cylinder pressure and the experimental trace for the baseline case and for a case with water injected at 3 bar and SOI $=0$ CAD aTDCf. We observe that the reduction of the pressure peak due to water injection is to some extent underestimated. The main reason is attributed to the long dynamics of the wall film accumulation and essentially it is due to a very slow liquid water film growth which does not reach quasi steady-state conditions in ten engine cycles. The details will be further discussed in Section 4.1.

\subsection{Water Spray Dynamics in the Intake Runner and Ports}

Focusing on the intake runner and ports, results of the liquid water dynamics for each simulation are presented in Figure 7. In each chart three curves are shown: the cumulated injected water mass, in red; the cumulated mass of the water that reaches the cylinder in liquid form, in light blue; and the accumulated wall film mass, in green. Vapor phase is not shown for clarity, as it can be easily inferred from the information on the liquid phase, being basically complementary.

First, we notice that none of the cases under investigation leads to null wall film mass, meaning that the engine operating conditions are not sufficient for vaporizing or stripping off the total amount of water impinging on the walls per cycle. Also, none of the cases have reached a steady state amount of accumulated wall film mass after ten cycles. Therefore, part of the water mass sticks to the walls and will not contribute to the anticipated scopes on the combustion mitigation. From these simulation results it is concluded that, in the engine point under consideration, more than ten cycles are needed to reach fully developed wall films and quasi-steady engine behaviors. From a computational standpoint, this would mean long and costly runs. To better explain this aspect related to the slow dynamics of the water wall film mass in the intake port, we extended one case up to twenty consecutive cycles, specifically the high injection pressure case, at 20 bar. Results are visible in Figure $7 \mathrm{~g}$, where the curves use the same colors for the first ten cycles, and then continue in gray until the twentieth cycle. As visible, the wall film mass shows a mild trend towards reaching a plateau, therefore towards a quasi-steady engine operation. For this specific case, the rate of development of the water wall film in the intake port divided by the injected water mass is also plotted in Figure 8. This percentage represents the amount of water that accumulates as wall film with respect to the total injected water mass. The trend is decreasing, as a function of the number of cycles, but still a perfectly steady film mass is not reached. As a consequence, a fraction of the injected water, on the order of $10 \%$, still does not contribute to slowing down the combustion rate. 


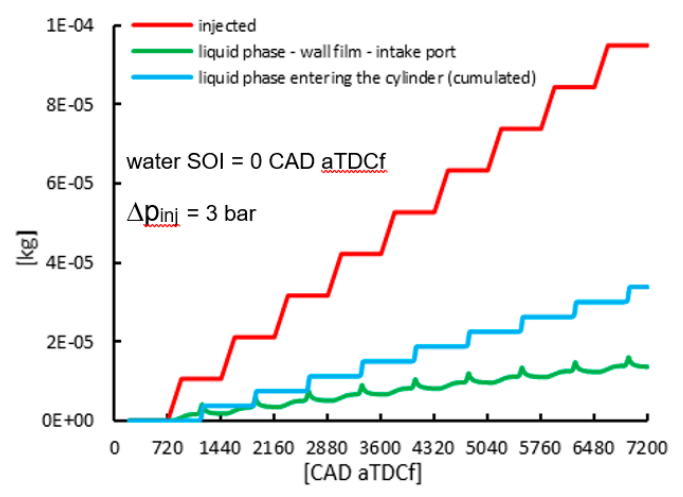

(a)

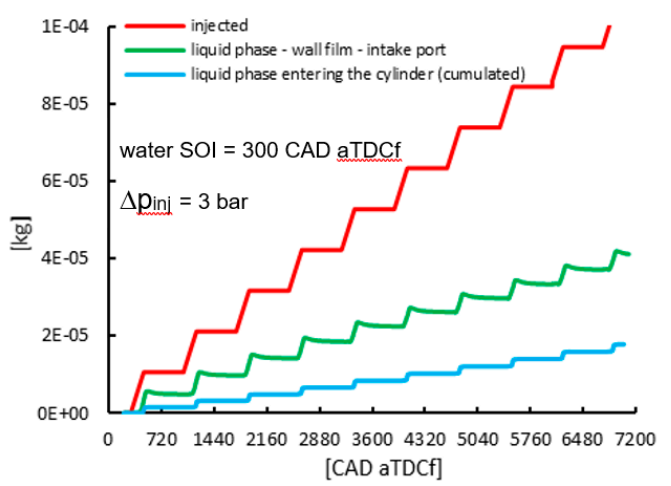

(c)

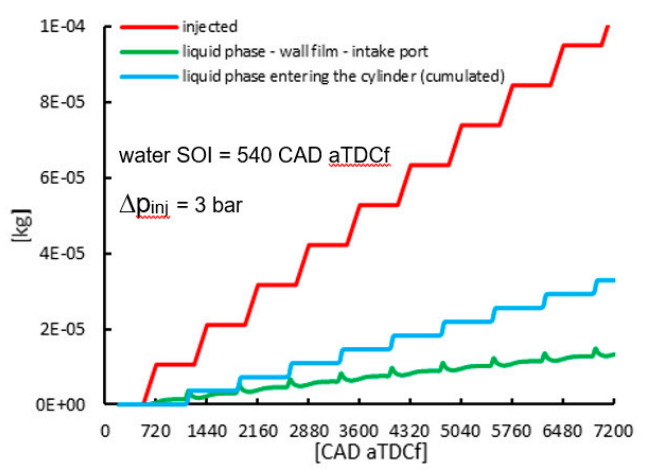

(e)

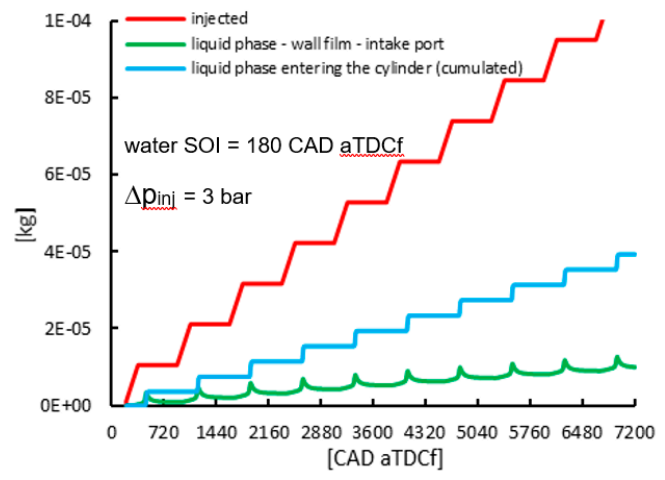

(b)

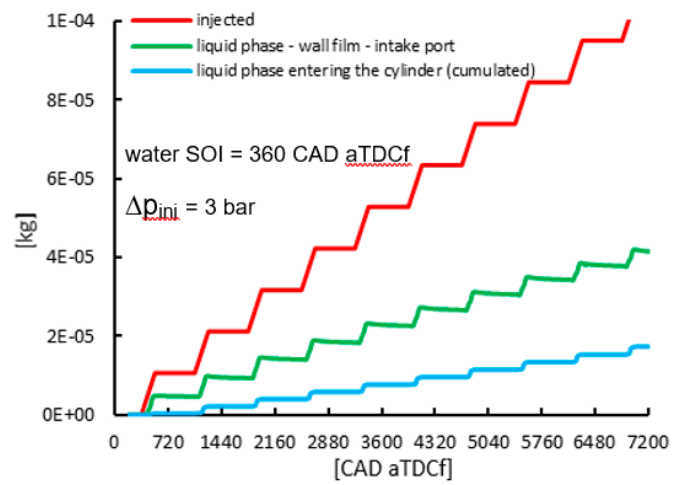

(d)

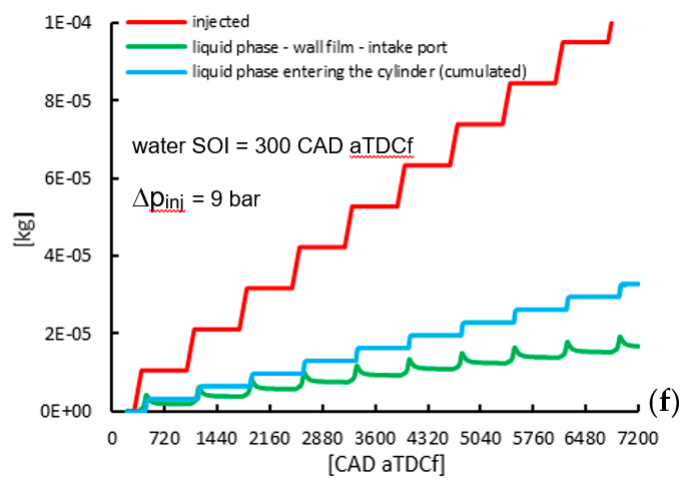

(f)

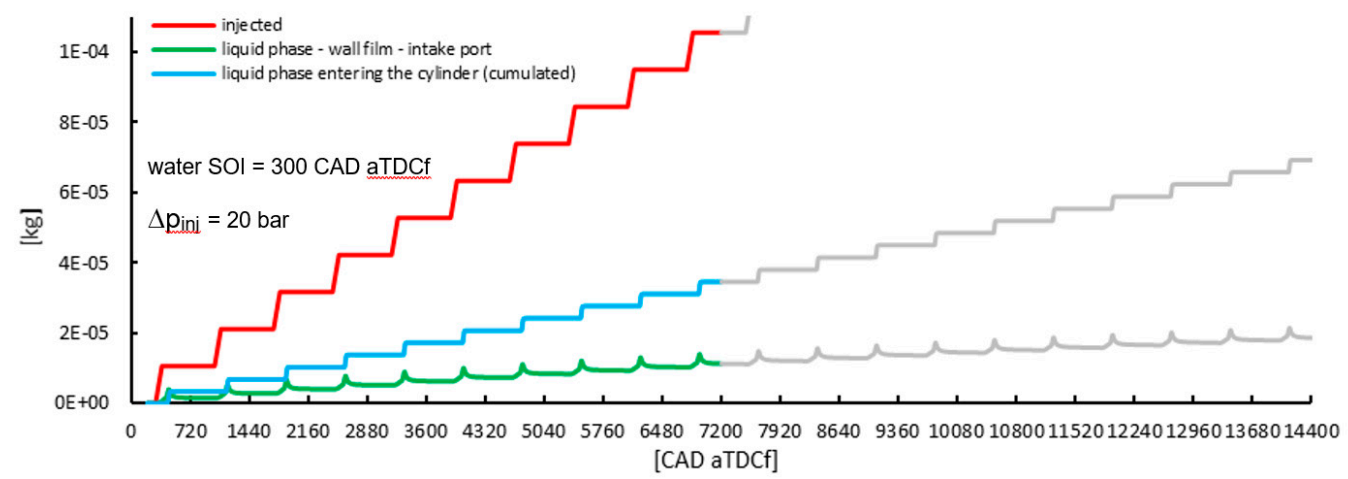

(g)

Figure 7. Dynamics of liquid water in the ports and runner, for each simulated case. (a) 3 bar- $\mathrm{SOI}=0$ CAD aTDCf; (b) 3 bar-SOI = 180 CAD aTDCf; (c) 3 bar-SOI = 300 CAD aTDCf; (d) 3 bar-SOI = 360 CAD aTDCf; (e) 3 bar-SOI = 540 CAD aTDCf; (f) 9 bar-SOI = 300 CAD aTDCf; (g) 20 bar-SOI = 300 CAD aTDCf. 


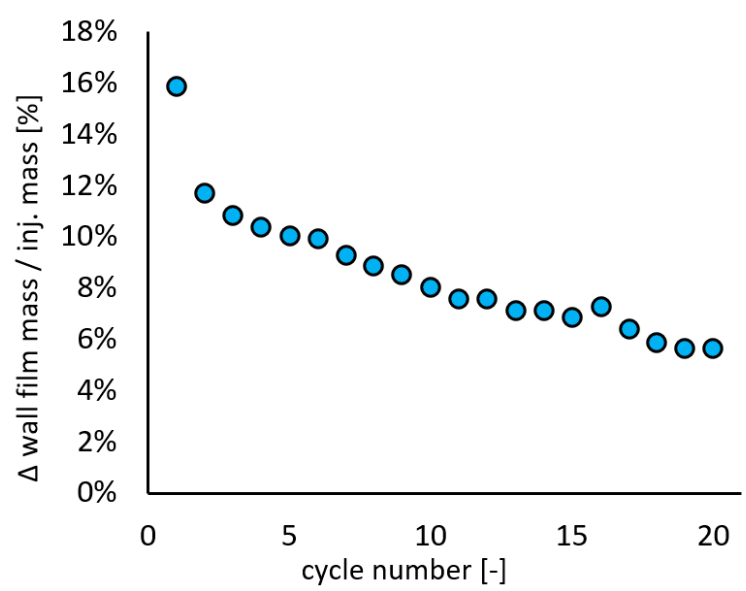

Figure 8. Behavior of the wall film mass during twenty cycles, for the high-pressure case (20 bar):

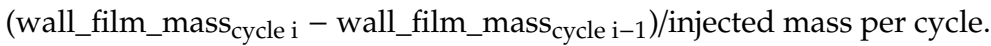

Coming back to the comparisons among different injection timings and pressures, in all the simulated cases shown in Figure 7, the water mass (liquid + vapor) entering the cylinder is slightly lower than the injected mass, because a fraction keeps accumulating in the wall film, decreasing the overall effectiveness and leading to an underestimation of the pressure peak reduction (as previously observed in Figure 6b). It is worth mentioning that this long wall film dynamics is likely due to the quite far installation of the water injector and also to the intermediate engine load point. It is expected that higher load points with higher operating temperatures, or closer injector installations could reduce the time scale of the phenomena and accelerate the combustion response to the actual amount of water injected. To facilitate the quantitative comparison of the results among the different cases, a synthetic report is also provided in Figure 9, which shows the percentages, with respect to the injected mass, of the liquid entering the cylinder and of the liquid accumulated on the wall after 10 cycles.

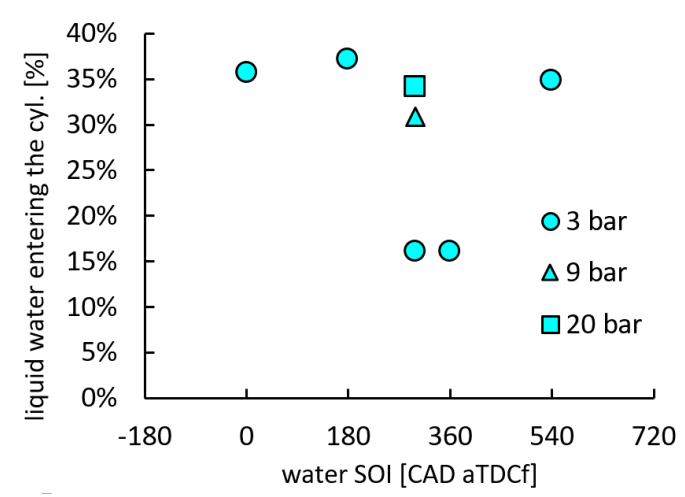

(a)

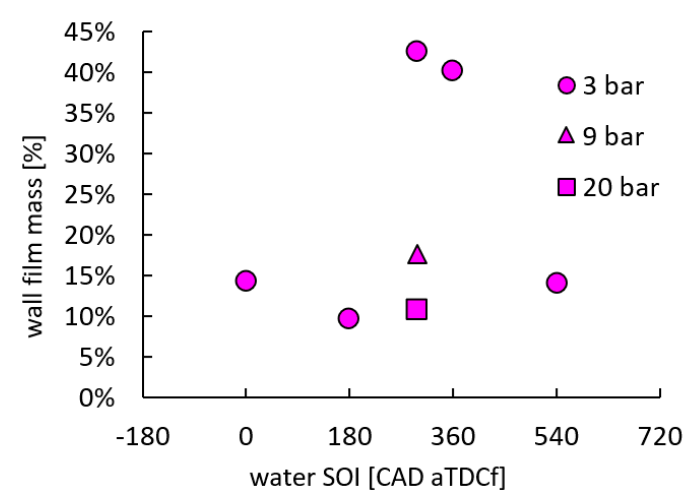

(b)

Figure 9. Liquid water balance in the ports and runner. Percentages refer to the injected water mass: (a) liquid water entering the cylinder; (b) wall film mass.

Figure 10 shows detailed visual results of the CFD calculations to better analyze the spray dynamics. Images are taken from the last cycle available, for each case. On the left column, we show the spray situation slightly before the IVO, at 340 CAD aTDCf, to appreciate how water droplets are distributed while approaching the intake phase, as a function of different SOI timings and injection pressures. On the right column, images refer to $460 \mathrm{CAD}$ aTDCf, which is during the intake phase. The relative comparison between images before and during the air intake is believed to give a clear idea of the spray evolution.

At 3 bar injection pressure the quantitative effect of the injection timing can be observed analyzing Figure 7a-e, and data plotted with circles in Figure 9. It is apparent that early SOI timings with respect 
to the intake phase, i.e. SOI of 540 CAD, 0 CAD and 180 CAD aTDCf, generate less wall film and more spray flows through the valves and reaches the cylinder as liquid. When water is injected around 300-360 CAD aTDCf, due to the quite long traveling distance between the injector location and the valves, water does not reach the cylinder immediately and large quantities of wall film are being formed. This effect is clearly visible in Figure 8, focusing for example on the case at 3 bar with SOI $=360$ CAD aTDCf. For this injection timing, the spray visible in the port at 340 CAD aTDCf is water left from the previous injection, while the new spray, being injected at 360 CAD aTDCf, still has to arrive. At 460 CAD aTDCf, when induction is taking place and the air flow is drawing water through the valves, it is clearly visible that the new spray is late, and most of it will not be able to enter the cylinder before IVC, therefore, remaining in the port for an entire cycle till the next valve opening. A similar behavior takes place with SOI $=300 \mathrm{CAD}$ aTDCf, where again large quantity of wall film is generated (cf. also wall film images at $300 \mathrm{CAD}$ and $360 \mathrm{CAD}$ aTDCf-3 bar).

Figure 9 summarizes these effects: with unfavorable injection timings up to $40 \%$ injected water goes into film mass, and only $15 \%$ liquid spray reaches the cylinder. Other timings cause about $10-15 \%$ of the injected mass to accumulate on the wall film, and about $35 \%$ liquid water is usefully introduced in the cylinder. It is worth noting that the remaining water mass vaporizes while in the port, and then it is drawn in as vapor (e.g. at SOI $=360$ CAD aTDCf, this amount is about $45 \%$ ).

In conclusion, we observe that, from the point of view of spray dynamics, the most effective timing at 3 bar injection pressure is the SOI $=180$ CAD aTDCf, which produces the lower amount of wall film and the largest amount of liquid water reaching the cylinder.

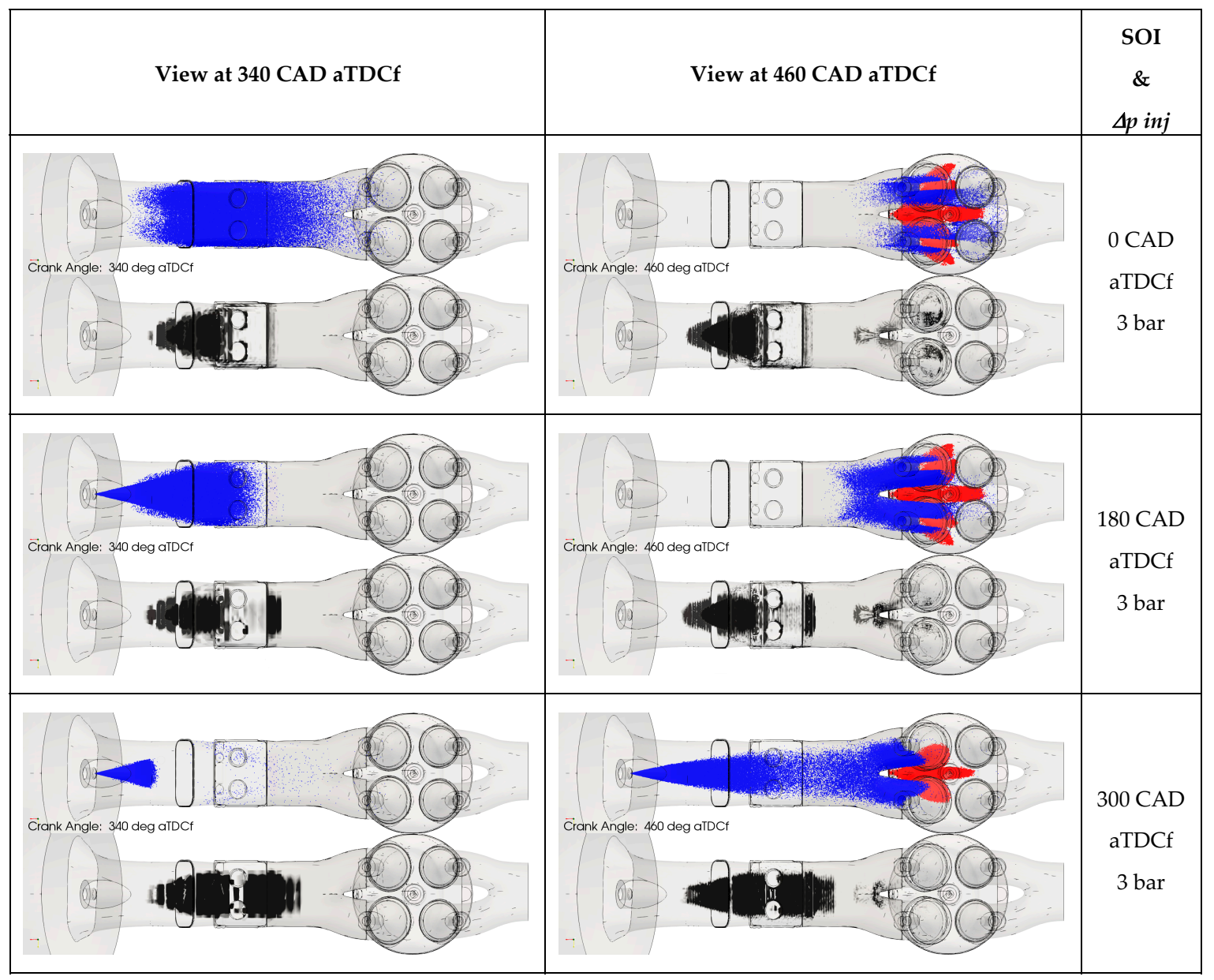

Figure 10. Cont. 


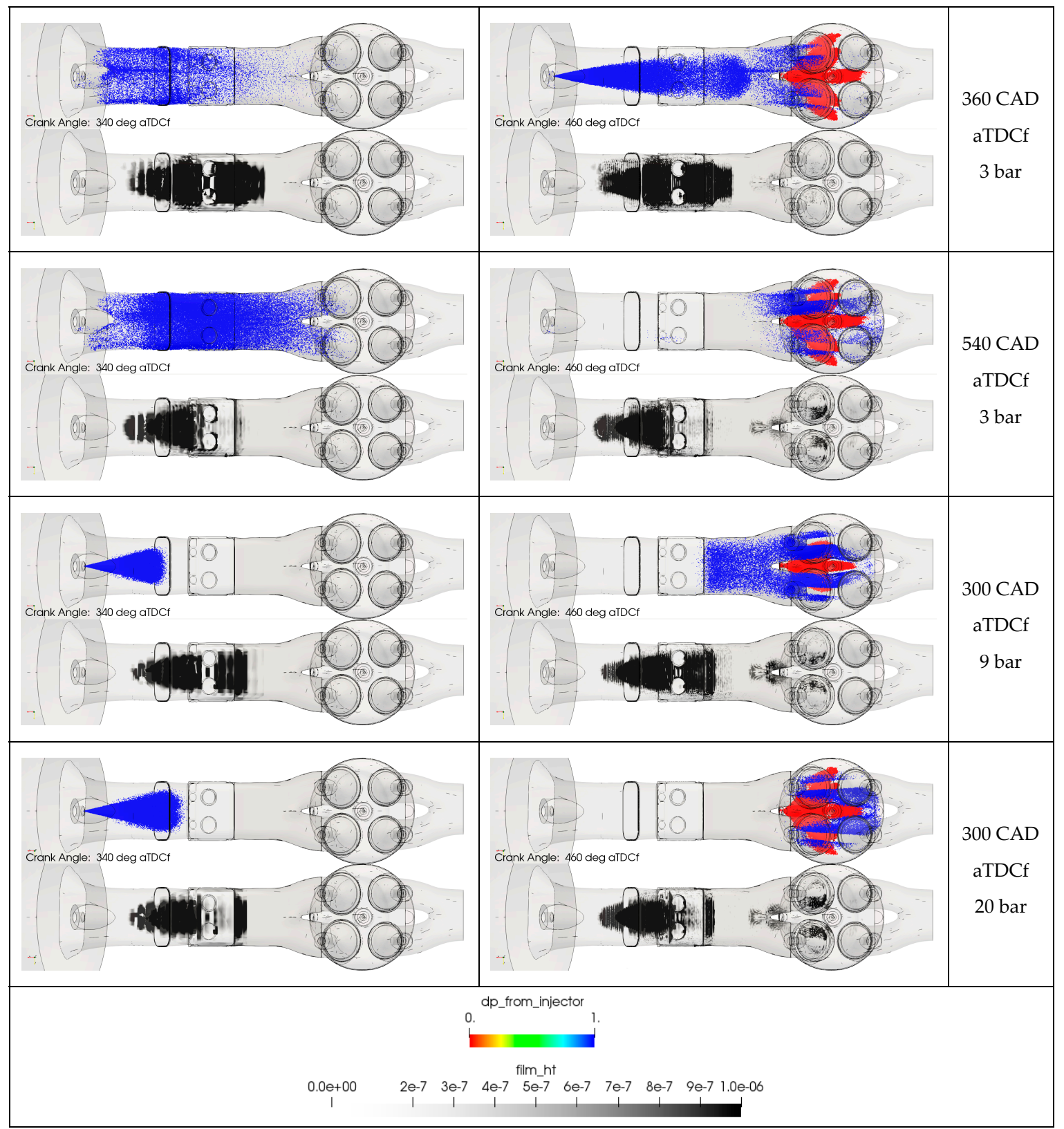

Figure 10. Visualization of CFD results with transparent geometry. Water sprays in blue and gasoline sprays in red, shown in the top images. Wall films in shades of gray, shown in the bottom images. Left column is at 340 CAD aTDCf, that is slightly before IVO. Right column is at 460 CAD aTDCf, during the air intake phase.

When comparing the 9 bar and 20 bar injection pressure cases against the low-pressure case, at 300 CAD aTDCF SOI in Figure 9, we observe a rather effective reduction of the wall film (about $0.4 x$ and $0.25 x$, respectively) and an increase of the in-cylinder trapped liquid water (about $2 x$ and 2.2x, respectively). This is in agreement with what has been already observed in [7] spanning various injection timings, suggesting that better atomization quality and shorter injection durations are potentially beneficial. Using higher injection pressure, the mass of liquid water entering the cylinder and evaporating with less wall contact increases substantially, therefore a larger impact is expected on the combustion.

One additional aspect that should be carefully checked is the saturation level of the water vapor phase. Figure 11 shows the comparison of a saturation index between the case at 3 bar-SOI 300 aTDCf and the case at 20 bar-SOI 200 aTDCf, for three different timings. A saturation index value equal to 0 
indicates the absence of water vapor phase, while a value equal to 1 indicates that the air is completely saturated with water vapor at the local temperature. Analyzing the first timing (SOI 300 aTDCf, that corresponds to the start of injection), for the low-pressure case, there is a region in the intake port where water vapor is already accumulated from previous cycles, while for the high-pressure case residual water vapor is basically absent. Observing the second timing, during the intake valve open, for the 20 bar case, the contours show that the vapor reaches the cylinder immediately following the liquid parcels (cf. Figure 10), while, for the 3 bar case, the vapor left from the previous cycle is entering the cylinder. Finally, analyzing the third timing, after intake valve closure, for the low-pressure case, we can appreciate how a large amount of vapor remains in the port until the next cycle reaching also saturated conditions, while, for the high-pressure case, the intake port has little amount of water vapor left, not entered in to the cylinder. Saturation is not a limiting factor for the high-injection pressure case, while it appears to be critical for the low injection pressure case.

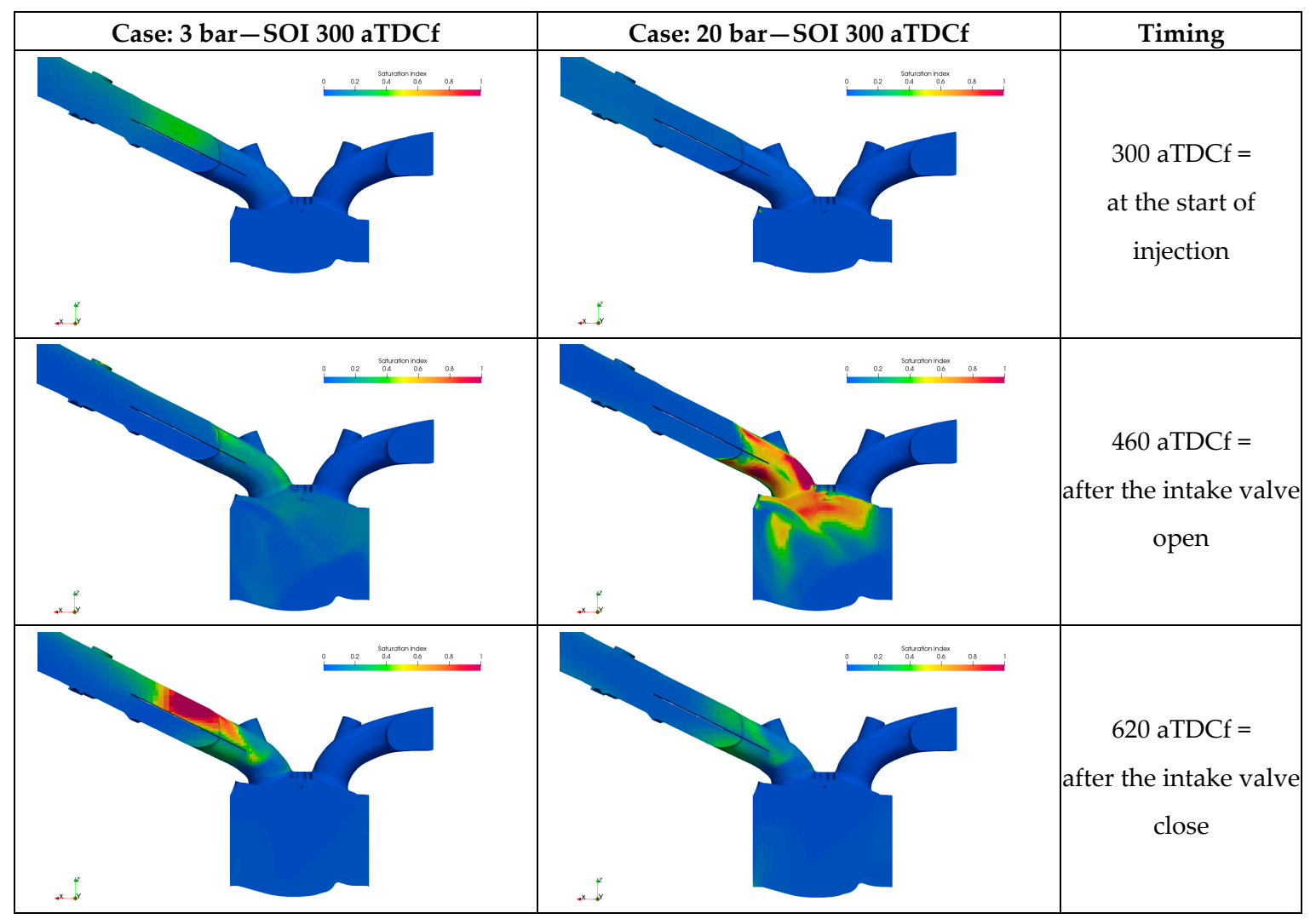

Figure 11. Comparison of saturation index between the case at 3 bar-SOI 300 aTDCf and the case at 20 bar-SOI 200 aTDCf, for three different timings.

Lastly, we also want to mention that no water wall impingement was observed on the cylinder liner, in none of the simulated cases, mainly because of the distant installation of the water injector. This is also very important, because it safeguards the life of the lubricant properties and of the engine durability itself.

\subsection{Impact on Combustion}

Ultimately, the goal of water injection is to affect combustion. A comprehensive summary of the water impact for the various cases is presented in Figure 12a shows the reduction of the pressure peak caused by the water addition, normalized with respect to the baseline case without water, for all cases compared to measurements. Figure $12 \mathrm{~b}$ quantifies how much the combustion is slowed down measured in terms of MFB50 (crank angle of 50\% mass fraction burned). Figure $12 \mathrm{c}$ reports the 
charge cooling effect, evaluated before the spark, as the decrease of in-cylinder temperature w.r.t. the no-water case.

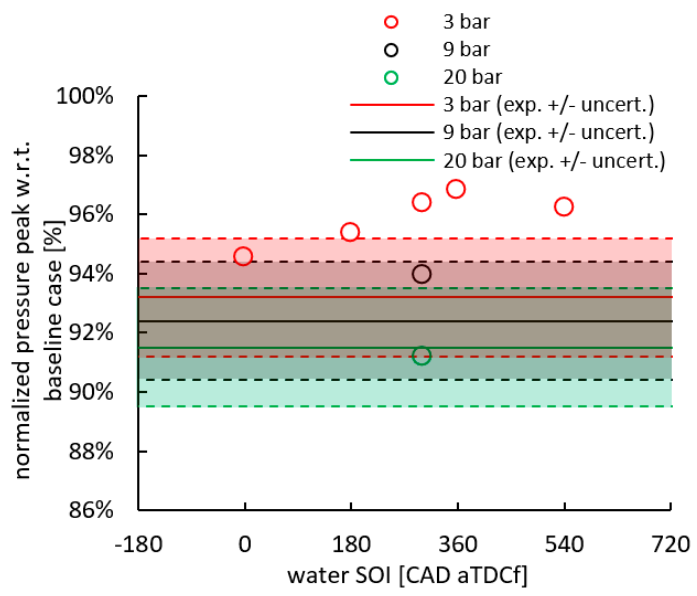

(a)

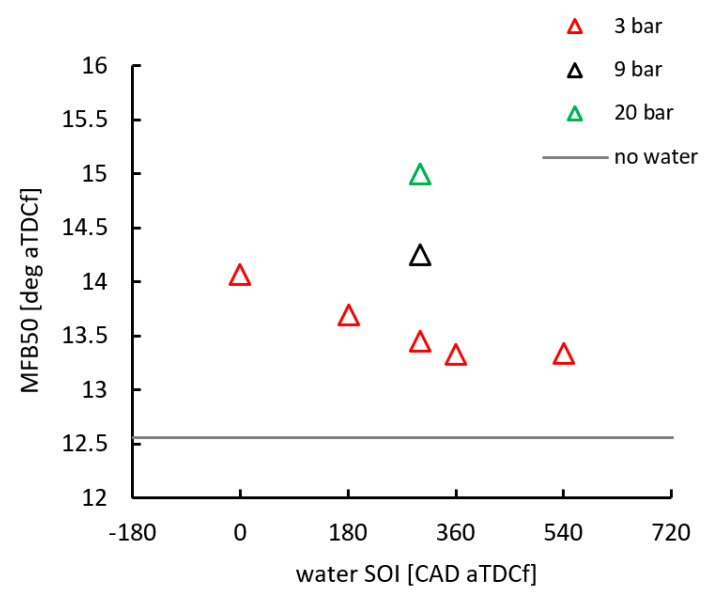

(b)

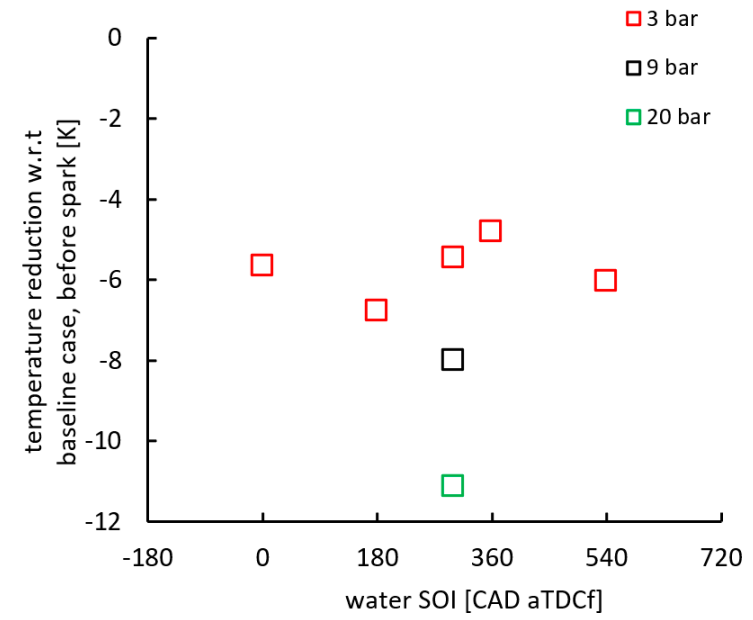

(c)

Figure 12. Water effect on (a) pressure peak; (b) combustion phasing; and (c) charge cooling before spark, at -20 CAD aTDCf. Spark timing is fixed at SA $=-14$ CAD aTDCf.

The reduction of the pressure peak which is achieved is in the order of $4-9 \%$ according to the simulations, while measurements suggest a reduction of about 7-9\%, depending on the pressure. Experimental data were acquired for several injection timings, but a clear trend was not observed, and an overall data scatter with about $\pm 2 \%$ uncertainty was recorded. We previously noted that the accumulated water wall film mass in the simulation is not quasi-steady after 10 cycles, therefore this can explain the reduced effectiveness provided by the model especially at low injection pressures. On the other end, a substantial agreement is found for the high injection pressure case because finer atomization promotes faster evaporation and reduces the wall fill mass shortening the engine response time. Focusing on the effect of the injection pressure, we observe that due to improved atomization level, at constant SOI timing, the charge cooling effect increases, the pressure peak reduction is more significant, and consistently the combustion slows down further.

Concerning the effect of the injection timing, at 3 bar we observe that the 300-360 CAD aTDCf cases behave as the worst, as the pressure peak is less reduced and the MFB50 is less retarded, in agreement with the previous conclusions on the spray dynamics (see results in Figure 9). The case at SOI $=0$ CAD aTDCf does not strictly follow this criterion though, and despite the trapped water was not the highest, it produces the strongest impact on the combustion. This can be explained including other combined side-effects. In particular, the amount of vapor being formed in the ports decreases the 
volumetric efficiency and alters the average equivalence ratio. In this case, being $\Phi=1$ in the baseline case, in the water cases the mixture tends to be slightly rich (injected fuel is kept constant) because of lack of oxygen replaced by vaporized water. This is more pronounced at 0 CAD aTDCf SOI and it explains the reduction of the combustion rate. In addition, as visible in Figure 12c, the effect of charge cooling for this case is not the largest at 3 bar, so the peak reduction is a result of a slight decrease of combustion efficiency, as the air-fuel ratio variations are not compensated in the models.

\section{Results under Similar KLSA}

Because water slows down the burn rate, the comparison in terms of performance must be made after the spark timing is re-adjusted to the same knock risk margin. As mentioned in the introduction and methods Sections, to do this we used the ECFM combustion model with tabulated autoignition data. We run sweeps of several spark timings, mapping the fields of the flow variables from the last available cycle and restarting the calculations with different SA timings to simulate the combustion. Starting from -14 CAD aTDCf, spark is advanced up to -28 CAD aTDCf. Results are shown in Figure 13 in terms of heat release rate (HRR), maximum amplitude of pressure oscillation (MAPO) detected on a local virtual pressure sensor, and lastly in terms of cylinder pressure under the same knock margin. MAPO is calculated by taking the difference of point pressure (in the most severe knock occurrence location identified) and average in-cylinder pressure, rectifying and taking the maximum; examples were documented in [7].

As these simulations are run using the RANS framework, without any model for predicting the statistical occurrence of knock, we only expect the results to be representative of an ensemble average behavior. Real knock is clearly non-linear and stochastic, but we are not modeling the likelihood of few cycles exhibiting knock. Therefore, results might not be comparable in absolute terms to experiments or expensive multi-cycle LES calculations, as to what concerns the capability of predicting the exact knock onset as SA is varied. However, the spark sweeps for various cases provide a consistent indication of the benefits achievable with water injection.

With this in mind, the HRR curve in Figure 13b shows that for the high-pressure case (20 bar, $\mathrm{SOI}=300 \mathrm{CAD}$ aTDCf), which was more effective on slowing down combustion (see previous Section), a sensible autoignition starts to take place at -28 CAD aTDCf, compared to the baseline case (Figure 13a) in which a sensible autoignition start to take place at -20 CAD aTDCf. Observing Figure $13 \mathrm{c}$ and considering that the MAPO knee is located at about -22 CAD aTDCf for the baseline no-water case, we conclude from the MAPO curves that about 2 CAD of spark advance are gained, in this engine point, using the low-pressure water injection (with SOI $=0$ CAD aTDCf which is the most effective case), and about $6 \mathrm{CAD}$ of spark advance are gained using the high-pressure water injection. The values found here are in very good agreement with engine measurements already reported in [9], for the same engine point. The benefits of a KLSA shift are shown in Figure 13d-e, comparing in-cylinder pressure and HRR curves. The IMEP is $1.8 \%$ higher for the low-pressure case, while for the high-pressure case the IMEP is $4.2 \%$ higher, therefore this improvement also translates to the overall thermal efficiency. 


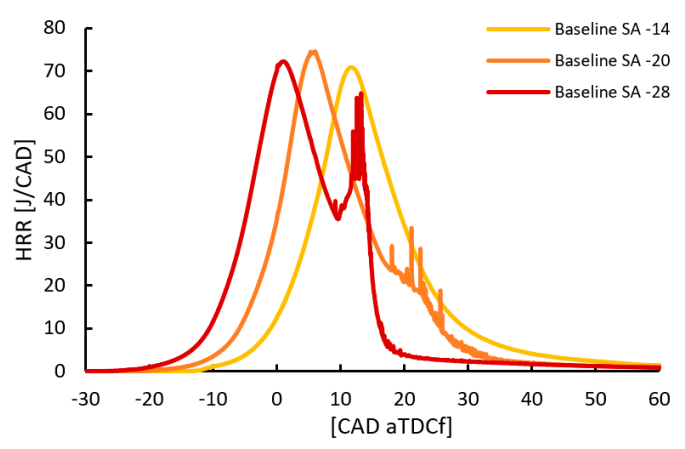

(a)

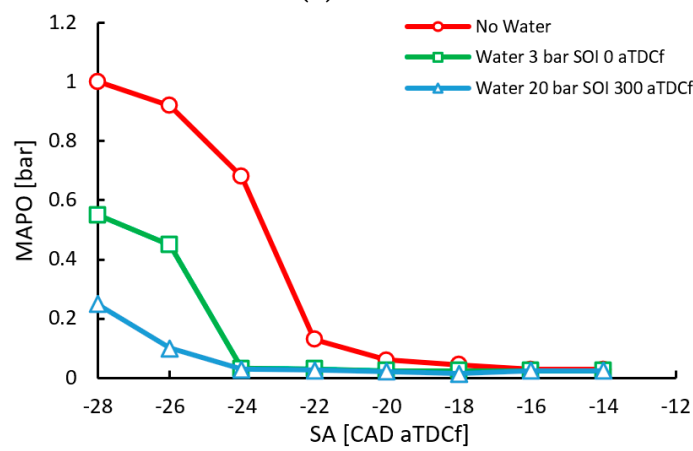

(c)

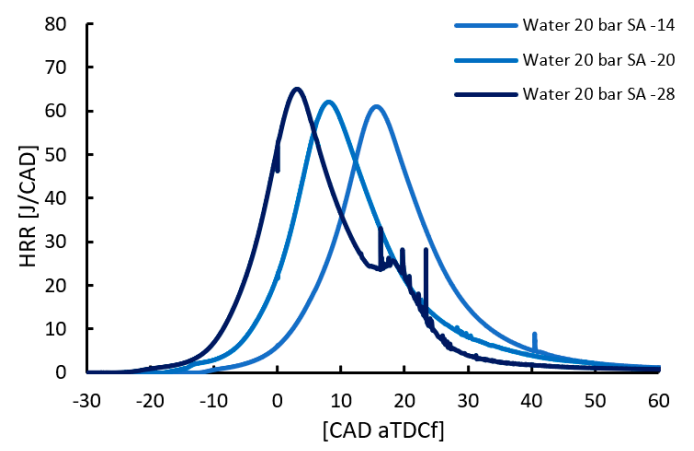

(b)

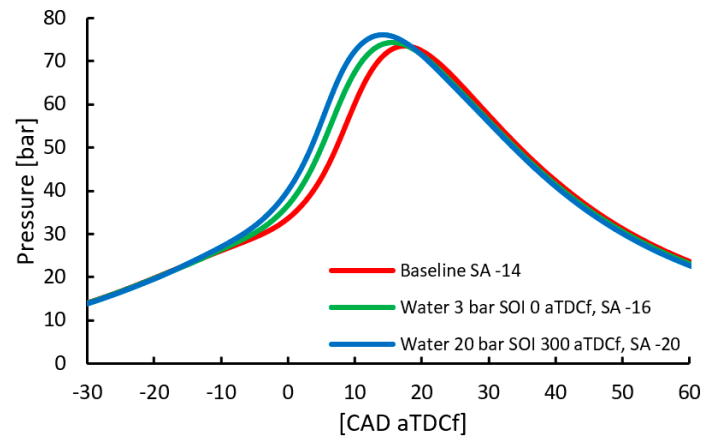

(d)

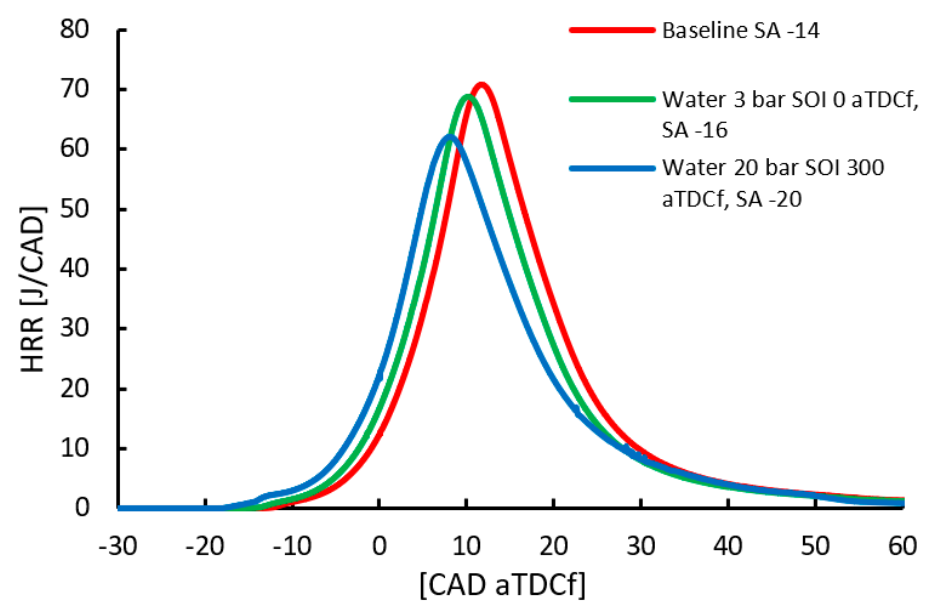

(e)

Figure 13. Effect of spark timing variation. Heat release rates for the baseline case w/o water (a) and for the case with water at 20 bar (b). MAPO vs. SA at 3 bar SOI $=0$ CAD and at 20 bar SOI $=300$ CAD aTDCf (c). In-cylinder pressure curves (d) and heat release rates (e), with and w/o water, under the same knock margin.

\section{Conclusions}

The work discusses the effects of PWI in a boosted GDI engine at medium speed and mid-load, under incipient knocking conditions, and it uses CFD models to analyze the impact and benefits of various water injection strategies. The work investigates the effect of water injection timing and pressure, providing quantitative results for water spray dynamics and charge cooling effects, which are rather difficult to assess experimentally. Also, the results compare favorably with available measurements in a specific engine point in terms of combustion behavior and efficiency gain.

Useful predictions can be achieved using a detailed CFD model, which can assist the design, development and optimization of water injectors and system architectures. Water injection timing clearly needs to be optimized, for a specific port installation position and operating conditions. 
In addition, the water atomization quality is found to be a tangible parameter for optimum effectiveness of WI. The study shows that an increase of the water injection pressure can lead to substantial benefits. Remarkably, despite the RANS modeling framework, the effects on the combustion behavior and on the shift of the KLSA are in agreement with measured data and with literature results.

Future work will be devoted to more extensive validation in multiple engine points, also considering different installation locations and injector designs, as well as different water-to-fuel ratios. From the modeling point of view, more accurate RANS models, like those proposed in [14,15], or LES models $[12,26]$ with multiple combustion realizations can be considered for further assessment.

Author Contributions: Conceptualization, M.B., N.C. and M.D.C.; software, J.Z. and M.B.; validation, J.Z. and M.B.; investigation, J.Z. and M.B.; resources, J.Z., M.B., F.R., N.C. and M.D.C.; data curation, J.Z., M.B., F.R. and N.C.; writing-original draft preparation, J.Z. and M.B.; writing-review and editing, J.Z., M.B. and N.C.; supervision, M.B., N.C. and M.D.C.

Funding: This research received no external funding.

Acknowledgments: The simulation work reported in this paper is supported by the HPC resources granted by the Italian Consortium Cineca, under the Iscra initiative-awards MSDyn, 2018, HI2FLOW, 2018 and CLOUD_openPG19, 2019—on the supercomputer Marconi.

Conflicts of Interest: The authors declare no conflict of interest.

\section{References}

1. Hoppe, F.; Thewes, M.; Baumgarten, H.; Dohmen, J. Water injection for gasoline engines: Potentials, challenges, and solutions. Int. J. Engine Res. 2016, 17, 86-96. [CrossRef]

2. Hoppe, F.; Thewes, M.; Seibel, J.; Balazs, A.; Scharf, J. Evaluation of the Potential of Water Injection for Gasoline Engines. SAE Int. J. Engines 2017, 10, 2500-2512. [CrossRef]

3. Thewes, M.; Baumgarten, H.; Scharf, J.; Birmes, G.; Balazs, A.; Lehrheuer, B.; Hoppe, F. Water Injection-High Power and High Efficiency Combined. In Proceedings of the 25th Aachen Colloquium Automobile and Engine Technology, Aachen, Germany, 10-12 October 2016.

4. Pauer, T.; Frohnmaier, M.; Walther, J.; Schenk, P.; Hettinger, A.; Kampmann, S. Optimization of Gasoline Engines by Water Injection. In Proceedings of the 37th International Vienna Motor Symposium, Vienna, Austria, 28-29 April 2016.

5. Bozza, F.; De Bellis, V.; Teodosio, L. Potentials of cooled EGR and water injection for knock resistance and fuel consumption improvements of gasoline engines. Appl. Energy 2016, 169, 112-125. [CrossRef]

6. Iacobacci, A.; Marchitto, L.; Valentino, G. Water Injection to Enhance Performance and Emissions of a Turbocharged Gasoline Engine under High Load Condition. SAE Int. J. Engines 2017, 10, 928-937. [CrossRef]

7. Battistoni, M.; Grimaldi, C.; Cruccolini, V.; Discepoli, G.; De Cesare, M. Assessment of Port Water Injection Strategies to Control Knock in a GDI Engine through Multi-Cycle CFD Simulations; SAE Technical Paper 2017-24-0034; SAE International: Warrendale, PA, USA, 2017.

8. Zhu, S.; Hu, B.; Akehurst, S.; Copeland, C.; Lewis, A.; Yuan, H.; Kennedy, I.; Bernards, J.; Branney, C. A review of water injection applied on the internal combustion engine. Energy Convers. Manag. 2019, 184, 139-158. [CrossRef]

9. Cavina, N.; Rojo, N.; Businaro, A.; Brusa, A.; Corti, E.; De Cesare, M. Investigation of Water Injection Effects on Combustion Characteristics of a GDI TC Engine. SAE Int. J. Engines 2017, 10, 2209-2218. [CrossRef]

10. Chen, B.; Zhang, L.; Han, J.; Chen, X. Investigating the effect of increasing specific heat and the influence of charge cooling of water injection in a TGDI engine. Appl. Therm. Eng. 2019, 149, 1105-1113. [CrossRef]

11. D'Adamo, A.; Berni, F.; Breda, S.; Lugli, M.; Fontanesi, S.; Cantore, G. A Numerical Investigation on the Potentials of Water Injection as a Fuel Efficiency Enhancer in Highly Downsized GDI Engines; SAE Technical Paper 2015-01-0393; SAE International: Warrendale, PA, USA, 2015.

12. Robert, A.; Richard, S.; Colin, O.; Poinsot, T. LES study of deflagration to detonation mechanisms in a downsized spark ignition engine. Combust. Flame 2015, 162, 2788-2807. [CrossRef]

13. Berni, F.; Breda, S.; Lugli, M.; Cantore, G. A Numerical Investigation on the Potentials of Water Injection to Increase Knock Resistance and Reduce Fuel Consumption in Highly Downsized G132DI Engines. Energy Procedia 2015, 81, 826-835. [CrossRef] 
14. D'Adamo, A.; Breda, S.; Iaccarino, S.; Berni, F.; Fontanesi, S.; Zardin, B.; Borghi, M.; Irimescu, A.; Merola, S. Development of a RANS-Based Knock Model to Infer the Knock Probability in a Research Spark-Ignition Engine. SAE Int. J. Engines 2017, 10, 722-739. [CrossRef]

15. Linse, D.; Kleemann, A.; Hasse, C. Probability density function approach coupled with detailed chemical kinetics for the prediction of knock in turbocharged direct injection spark ignition engines. Combust. Flame 2014, 161, 997-1014. [CrossRef]

16. Chevillard, S.; Colin, O.; Bohbot, J.; Wang, M.; Pomraning, E.; Senecal, P.K. Advanced Methodology to Investigate Knock for Downsized Gasoline Direct Injection Engine Using 3D RANS Simulations; SAE Technical Paper 2017-01-0579; SAE International: Warrendale, PA, USA, 2017.

17. Richards, K.J.; Senecal, P.K.; Pomraning, E. CONVERGE v.2.4 Documentation; Convergent Sciences Inc: Madison, WI, USA, 2017.

18. Senecal, P.K.; Pomraning, E.; Richards, K.J.; Som, S. Grid-Convergent Spray Models for Internal Combustion Engine Computational Fluid Dynamics Simulations. ASME J. Energy Resour. Technol. 2014, 136, 012204-1. [CrossRef]

19. Yakhot, V.; Orszag, S.A. Renormalization group analysis of turbulence. Basic theory. J. Sci. Comput. 1986, 1, 3-51. [CrossRef]

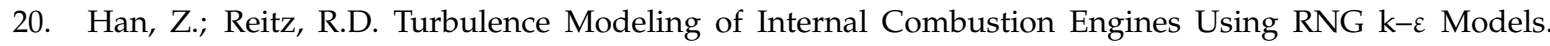
Combust. Sci. Technol. 1995, 106, 267-295. [CrossRef]

21. Peters, N. Turbulent Combustion; Cambridge University Press: Cambridge, UK, 2000.

22. Gulder, O.L. Correlations of Laminar Combustion Data for Alternative S.I. Engine Fuels; SAE Technical Paper 841000; SAE International: Warrendale, PA, USA, 1984.

23. Metghalchi, M.; Keck, J.C. Burning Velocities of Mixtures of Air with Methanol, Isooctane and Indolene at High Pressure and Temperature. Combust. Flame 1982, 48, 191-210. [CrossRef]

24. Andrae, J.C.G.; Brinck, T.; Kalghatgi, G.T. HCCI experiments with toluene reference fuels modeled by a semidetailed chemical kinetic model. Combust. Flame 2008, 155, 696-712. [CrossRef]

25. Neal, M.; Smallbone, A.; Bhave, A.; Kraft, M.; Cracknell, R.; Kalghatgi, G.T. Mapping surrogate gasoline compositions into RON/MON space. Combust. Flame 2010, 157, 1122-1131. [CrossRef]

26. Zembi, J.; Mariani, F.; Battistoni, M. Large Eddy Simulation of Ignition and Combustion Stability in a Lean SI Optical Access Engine; SAE Technical Paper 2019-24-0087; SAE International: Warrendale, PA, USA, 2019. 